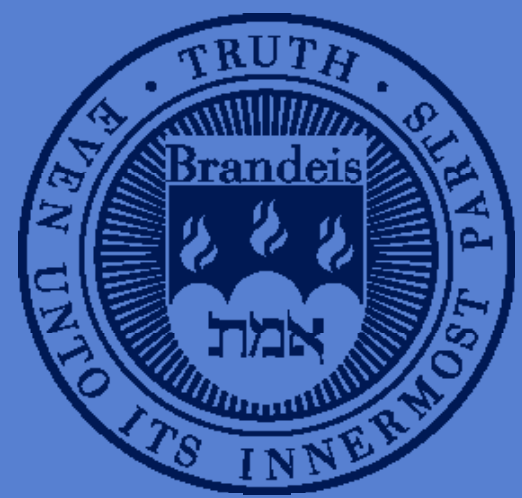

\title{
The Evolution of U.S. Spectrum Values Over Time
}

Michelle Connolly, Department of Economics, Duke University

Nelson Sa, Department of Economics, Brandeis University

Azeem Zaman, Department of Statistics, Harvard University

Chris Roark, Department of Economics, University of Chicago

Akshaya Trivedi, Trinity College, Duke University, Class of 2018

Working Paper Series 


\title{
The Evolution of U.S. Spectrum Values Over Time
}

\author{
Michelle Connolly ${ }^{1}$, Nelson Sá2, Azeem Zaman², \\ Chris Roark ${ }^{4}$, and Akshaya Trivedi ${ }^{5}$
}

February 13, 2018

\begin{abstract}
$\underline{\text { Abstract }}$
We consider 1997 to 2015 data from FCC spectrum auctions related to cellular services to attempt to identify intrinsic spectrum values. Relative to previous literature, we control for license specific auction rules, and introduce measures to separate out technological progress that effectively reduces spectrum scarcity from progress that increases demand. Results confirm that technological changes have led to increases in the relative value of higher frequencies. Surprisingly, 47 percent of these licenses have been won by "small" bidders, representing 27 percent of the real value of these licenses. The use of bidding credits further appears to consistently reduce auction competition.
\end{abstract}

Keywords: Spectrum, Spectrum Scarcity, Auctions, FCC, Auction Rules, Mobile Applications, Spectral Efficiency, Broadband Speeds, Closed Auctions, Small Bidders, "The Google Effect"

JEL Codes: L5, O3, K2

${ }^{1}$ Corresponding author: Michelle Connolly, mconnoll@duke.edu, 213 Social Sciences, Box 90097, Department of Economics, Duke University, Durham, NC 27708. ${ }^{2}$ Department of Economics, Brandeis University. ${ }^{3}$ Department of Statistics, Harvard University. ${ }^{4}$ Department of Economics, University of Chicago. ${ }^{5}$ Trinity College, Duke University Class of 2018. We gratefully acknowledge the support of NSF grant 1314468. We benefited from particularly helpful feedback from Thomas Hazlett, Evan Kwerel, and Leslie Marx. We thank Richard Clark, David Salant, Pierre de Vries, and participants at the 2017 TPRC conference for comments and suggestions. We also thank Repton Salisbury, Andrew Heiss, Jie Chen, Levi Crews, Jennifer Garand, Suhani Jalota, Clement Lee, Tammy Lee, Jin Liu, Frances Mitchell, Gerald Ren Hao Tan, Chris Kehan Zhang, and Peng Xie for research assistance. The authors remain responsible for any errors. 
Evolution of spectrum values 2

\section{INTRODUCTION}

The National Broadband Plan released by the Federal Communications Commission in 2010 set the goal of making $500 \mathrm{MHz}$ of spectrum newly available for broadband within ten years, $300 \mathrm{MHz}$ of which would be allocated for mobile use within five years (FCC, 2010). A good assessment of spectrum value and a deeper understanding of its determinants is likely to increase efficiency in the allocation of this asset. For instance, accurate valuations may help set adequate reserve prices in spectrum auctions or tender processes, avoiding scenarios where demand is arbitrarily discouraged from the outset. Similarly, the International Telecommunication Union suggests that value estimations can be used by regulators to set the levels of recurring (or even upfront) fees in the context of administered incentive pricing (ITU, 2012). Barriers to trade in secondary markets may be reduced as well, making it easier to reach an optimal price point for spectrum transactions. In this respect, Ofcom regards the lack of information on the private value of spectrum to be one potential impediment to trading between commercial buyers and sellers (Marks et al., 2009).

The Federal Communications Commission lists a generic set of spectrum value determinants, including dimensions like location, technical characteristics, bandwidth, geographic area covered, availability of technology, amount of spectrum already available for similar services, the number of incumbents presently occupying the spectrum and whether they will be relocated (FCC, 1997). These variables may be separated into intrinsic and extrinsic factors (ITU, 2012). Intrinsic factors are unique to each set of frequencies. For example, propagation characteristics are specific to frequency levels; lower frequencies ensure more depth (higher penetration) and breadth (signals travel farther) in coverage, reducing necessary infrastructure costs. ${ }^{1}$ Extrinsic factors include a variety of physical, socio-economic and political market characteristics, including policy and regulatory encumbrances. Demographics, population density and income levels are some of these determinants, along with geography and climate which may affect maintenance costs. Regulatory obligations like open access, build-out or

\footnotetext{
${ }^{1}$ Crampton (2012) argues that anti-competitive screenings ought to weight spectrum holdings in different bands with distinct relative values to capture their varying quality, all else constant.
} 


\section{Evolution of spectrum values 3}

coverage requirements, etc. also impose external costs on spectrum access. For example, Ford et al. (2008) estimate that open access requirements imposed upon the upper $\mathrm{C}$ block of the 700 $\mathrm{MHz}$ auction in the United States may have reduced bids by as much as $40 \%$. Conversely, Dippon (2009) determines that set-aside provisions designed to protect new entrants in the Canadian AWS spectrum auction largely explained a premium of more than $100 \%$ in winning bids on unrestricted licenses, compared to similar spectrum in the United States. ${ }^{2}$ Similarly, Ayres and Cramton (1996) argue that bidding preferences led to overall increased government auction revenues. The design and implementation of competitive bidding therefore prompts fluctuations in the value assigned by economic agents to spectrum (Klemperer, 2002a; Klemperer, 2002b; Hazlett, 2008; Hazlett and Muñoz, 2009; Hazlett, Munoz and Avanzini, 2012). ${ }^{3}$

Previous attempts at deriving a service-neutral model of spectrum value found this task unfeasible given the underlying heterogeneity of network infrastructures and product content across diverse spectrum applications (Marks et al., 2009). We therefore focus on the valuation of spectrum purchased for mobile applications.

Auction results also vary over time and by country on otherwise similar transactions, raising the challenge of identifying appropriate controls for institutional, technological and market specificities. From that perspective, our use of highly disaggregated U.S. regional data offers us a large range of variability on key demographic and economic indicators within a common auction design framework and national environment. We do not attempt to make any estimates of total social welfare as done in Hazlett and Muñoz (2009), instead focusing on the market valuation by private firms.

The econometric relation between macroeconomic variables, regulators choices embedded in auction design, and post-auction award obligations are examined by Bohlin et al.

\footnotetext{
${ }^{2}$ Unrestricted spectrum refers to spectrum that is not set-aside for specific bidder types during its auctioning.

${ }^{3}$ As stated by Hazlett and Muñoz (2009), “....auction rules that alter market structure or operator performance produce welfare effects, and these spillovers may not be systematically incorporated. For instance, arguments are often advanced to improve license auctions by imposing reserve prices, extending credits to 'weak bidders,' or restricting the number of licenses (to increase scarcity value). In addition, the social discount rate is ignored in the auction processes that delay productive use of frequencies for months or years." p. 425.
} 


\section{Evolution of spectrum values 4}

(2010). However, their sample is limited to 83 observations, derived uniquely from national 3G spectrum licenses from various countries, excluding the United States. Wallsten (2013) considers over 63,000 licenses in post 1996 FCC auctions. He controls for economic uncertainty, year fixed effects, as well as certain factors such as paired bands, and "use" designations by the FCC.

To date, no papers have systematically categorized the full range of license specific rules, or controlled for both supply side and demand side changes in technology beyond using a simple time trend or year fixed effects. A time trend is useful for approximating technological changes over time but has three distinct limitations. First, it applies to all licenses/markets equally. This means that it may explain some of the variation in auction prices over time, but is unable to explain any cross-sectional variation by market. Second, the time trends typically considered are linear, whereas there is a fair amount of evidence that technological advances in telecommunications are non-linear, underscoring the fact that time trends are not actual estimates of technology. Third, and perhaps most importantly, since it is a rudimentary proxy for all types of technological progress, a time trend conflates different types of technological progress which impact spectrum values in opposing ways. Specifically, some types of technological progress increase the efficiency with which all spectrum is used. All else equal, these reduce the scarcity of our finite spectrum and lower auction prices. Other types of technological progress, such as the invention of wireless devices, smartphones, etc. push up demand for cellular services and in turn, demand for spectrum. All else equal, this puts upward pressure on auction prices.

Year fixed effects have similar problems to a simple time trend. Namely, they are also national in nature and conflating different types of technological progress. Moreover, when considering only auctions related to cellular services, there is frequently only one auction per year in the U.S. Hence, year fixed effects end up being almost identical to auction fixed effects and so are capturing a multitude of effects including auction specific regulations, technology levels, annual economic conditions, etc.

In addition, technological change can affect the relative worth of different frequencies. For example, new millimeter wave cellular systems targeted at 28 and $38 \mathrm{GHz}$ frequencies within $5 \mathrm{G}$ networks permit thousands of times greater data throughput to cell phones than 


\section{Evolution of spectrum values 5}

previously (Rappaport et al., 2013). We therefore wish to proxy for technological changes which occurred from 1997 to 2015 to reflect both improved abilities to use finite amounts of spectrum, and improved abilities to use higher frequency spectrum over time. We further attempt to control for other types of technological changes and market variations in infrastructure which drive increases in data traffic and inherent demand for spectrum.

Finally, we control for license specific auction rules. To date, no single data set has catalogued the multitude of FCC rules relevant to different licenses, blocks and auctions over time. To achieve this, we canvassed the individual auction rules for each of the 22 auctions related to mobile applications, creating a new comprehensive data set on specific types of rules imposed over time and within different license blocks (Connolly, Salisbury, Trivedi and Zaman, 2017).

\section{BACKGROUND: FCC AUCTION MECHANISMS AND RULES}

Spectrum is the set of radio frequencies that serve as inputs into the provision of wireless services - including, but not limited to radio, paging, and cellular devices. Spectrum has long been used by commercial and public entities, although its regulation has dramatically changed over the past 20 years.

The FCC plays an important regulatory role by allocating spectrum licenses for the right to use a given frequency band within a given geographic area. ${ }^{4}$ Initially provided on a first-comefirst-serve manner, the FCC later issued licenses through beauty contests and lotteries (Bohlin et al., 2010; Rosston, 2014). In beauty contests, mobile network operators submitted proposals for how they intended to use the license. The FCC chose what it considered the best plan, and awarded that operator the license. This administrative process, however, took several years, lacked transparency, and was susceptible to significant lobbying efforts (Cramton, 2001). Similarly, lotteries led to inefficient allocations because licenses were randomly awarded to

\footnotetext{
${ }^{4}$ We provide only a cursory overview here. For a detailed description of the evolution of the FCC's spectral allocation process see Rosston (2014).
} 


\section{Evolution of spectrum values 6}

applicants. This process attracted huge numbers of applicants, many of whom "lacked the technical expertise to run a cellular-telephone service." ${ }^{5}$ Even worse, given low application costs, many applications were solely submitted in the hopes of extracting rents through the resale of "won" spectrum to more efficient users (Rosston, 2014). Recognizing these pitfalls, the FCC transitioned to auctioning spectrum after Congress passed the Omnibus Budget Reconciliation Act in 1993 (Kavalar, 2013). In principle, these auctions are meant to allocate licenses to companies that most value, and can make the best use of the corresponding spectrum.

FCC auctions are simultaneous, ascending-bid auctions. During the auction, all licenses are available, and bidders can make offers on multiple licenses at a time. The auction continues over many rounds, until no more bids are made on any of the licenses. At this point, the auction ends and bidders win all the licenses for which they have the current highest bids (Fox and Bajari, 2013; Cramton, 2001).

The FCC writes specific rules for each auction ostensibly to enhance social welfare and achieve specific public policy outcomes, some of which were set by Congress when it granted the FCC authority to use auctions for spectrum allocations in the Omnibus Budget Reconciliation Act. These rules have substantial implications on auction outcomes. Here we give an overview of two key rules associated with FCC auctions.

Certain licenses are set-aside for entrepreneurs, entities that have "earned less than $\$ 125$ million in gross revenues during each of the two years prior to the auction and ...[have]... assets of less than $\$ 500$ million when filing ...[their]... application to participate." ${ }^{\prime 6}$ For example, in Broadband PCS auctions, C and F block licenses were originally set-aside exclusively for entrepreneurs (i.e. in closed bidding) (CBO, 2005). However, a regulatory change in 2000 led to the offering of certain $\mathrm{C}$ and $\mathrm{F}$ block licenses in open bidding. ${ }^{7}$

\footnotetext{
${ }^{5}$ McMillan (1994), p. 4.

${ }^{6}$ CBO (2005), p. 7.

7 The multiple changes to the set aside criteria created by the FCC's 2000 "Sixth Report and Order and Order on Reconsideration" are the primary reason that it is not sufficient to use simple block dummies to estimate the impact of closed auctions on winning bids.
} 


\section{Evolution of spectrum values 7}

In addition to licenses set aside for "closed" auctions, the FCC also grants bidding credits to specific businesses, referred to as "designated entities". Designated entities were originally defined as small businesses, businesses owned by minorities and/or women, and rural telephone companies. ${ }^{8}$ Competitive bidding rules, released before each auction, specify the size of credits designated entities may receive, which designated entities are eligible for credits, the licenses that may be bid on using credits, and a host of other criteria. Beginning with Auction 5 in 1995, small businesses received credits depending on their gross revenues. Currently, businesses with average gross revenues of up to $\$ 15$ million are designated as "very small businesses" and receive credits worth $25 \%$ of their winning bids. Businesses with average gross revenues of up to $\$ 40$ million in the three years preceding an auction are eligible to receive credits of $15 \%$ of their winning bids. ${ }^{9}$ The rules and procedure for choosing closed licenses changed in 2000, making fewer closed licenses available (FCC, 2000). This followed the observation of a large incidence of bankruptcy filings and payment defaults by $\mathrm{C}$ and $\mathrm{F}$ block licenses before and after Auction 22, covering a population ("pops") of approximately 191 million. Open bidding became thus favored in larger markets where the demand for spectrum by existing carriers was the greatest and the prospects of a spectrum shortage most acute. This policy shift is reflected in the fact that $42 \%$ of cellular licenses from 1997-2000 were offered in closed auctions. After 2000 , only $5.25 \%$ were offered as set-asides for designated entities.

The recent AWS-3 auction highlights, nonetheless, how large players may still attempt to exploit these rules. In a largely publicized case, the FCC retroactively denied two small entities, SNR Wireless and Northstar Wireless, bidding credits worth 3.3 billion dollars after uncovering that they were controlled and bankrolled by Dish Network (FCC, 2015). ${ }^{10}$

\footnotetext{
${ }^{8}$ Code of Federal Regulations, 47 C.F.R. $\S 1.2110,2016$. The FCC rules for qualification as a designated entity have evolved over time and are described more fully in Connolly et al. (2017a).

${ }^{9}$ Code of Federal Regulations, 47 C.F.R $§ 24.720(b), 2016$.

${ }^{10}$ In 2017, the D.C. Circuit U.S. Court of Appeals found that "(1) The FCC reasonably applied its longstanding precedent to determine that DISH exercised a disqualifying degree of de facto control over SNR and Northstar; but (2) the Commission did not give SNR and Northstar adequate notice that, if their relationships with DISH cost them their bidding credits, the FCC would also deny them an opportunity to cure. As a result, we remand this matter to the FCC to give petitioners an opportunity to seek to negotiate a cure for the de facto control the FCC found that DISH exercises over them." No. 15-1330.
} 


\section{Evolution of spectrum values 8}

In the first years of auctions, the FCC also granted designated entities the opportunity to pay for their licenses in installments. ${ }^{11}$ However, the ensuing speculation and defaults created by these attractive terms which had been offered in a total of six auctions prompted the FCC to discontinue using installment payments (Kwerel and Rosston, 2000; Cramton, 2001). This is one of the main reasons that we here only focus on post 1996 auction results.

While the designated entity measures were intended to boost competition and social welfare, evidence from Personal Communication Services (PCS) auctions suggests these measures were counterproductive. Within a decade of the auctions' end, many small businesses had transferred their licenses to larger companies. In addition, economically viable spectrum was left fallow, imposing significant social costs. Finally, the federal government likely lost receipts in the process (CBO, 2005).

License transfers from small to bigger companies were frequent within 10 years of the auctions' end. Until 2000, FCC regulations imposed penalties on companies who won licenses using small bidder preferences, and then transfer those licenses-within 5 years of the auction's end - to companies that did not initially qualify (FCC, 2000). ${ }^{12}$ Ascertaining the true rate of transfers before 2000 necessitates observing license ownership both during and after this penalty period. For example, Auction 11 ended in 1997; by 2004, more than 50\% of the total potential PCS coverage (100 percent coverage implies that all bandwidth is available to serve all the population) had been transferred from small to large entities. For Auction 22 (which ended in 1999), 40\% had been transferred (CBO, 2005). Such transfer rates indicate that small bidder preferences were generally unsuccessful in their goal of promoting sustained entry of smaller carriers.

\footnotetext{
${ }^{11}$ In this system, designated entities would put down $5 \%$ of the license award at the auction's end, another $5 \%$ when the license was awarded, and then pay "... quarterly installment payments at the 10 -year Treasury rate with interestonly payments for the first 6 years." Cramton (2001), p. 18.

12 In 2000, the FCC announced that it would no longer apply "...entrepreneur eligibility restrictions to the assignment or transfer of control of $\mathrm{C}$ and $\mathrm{F}$ block licenses won in open bidding" and that "upon satisfaction of the first construction benchmark for a license won in closed bidding, the control group of any eligible entrepreneur may assign or transfer control of $\mathrm{C}$ block licenses to a non-entrepreneur." p. 3. The FCC further removed the unjust enrichment payment requirement for all licenses won in Auctions 5 and 10 where all participants had received a 25 percent bidding credit.
} 
Evolution of spectrum values 9

Furthermore, small bidder preferences are economically and socially costly. In the earliest auctions, small bidder preferences were exclusively available in $\mathrm{C}$ and $\mathrm{F}$ blocks. In Auction 4, when A and B block licenses were offered in open bidding, potential PCS coverage measured close to $100 \%$ within months of the auction's closing. However, Auctions 5 and 10, both comprised solely of $\mathrm{C}$ block licenses, did not experience the same success. Winning bidders in these auctions ended up returning licenses to the FCC for re-auction, accounting for one-third of the potential PCS coverage available in Auctions 5 and 10. Furthermore, many licenses offered in Auctions 5, 10 and 11 to small bidders became contested in court-these licenses accounted for up to $33 \%$ of PCS coverage available from licenses given to small bidders (CBO 2005). Licenses that were contested in court or otherwise returned to the FCC could not be used for years, resulting in poorer coverage and higher prices. Rough estimates suggest the cost of letting the allocated spectrum lay fallow was upwards of $\$ 40$ billion (CBO, 2005).

Finally, federal government revenues from auctions were likely lower as a result of providing small bidder preferences. ${ }^{13}$ In general, small bidders paid less for licenses than they would have otherwise in competition with larger bidders. In Auction 11, small bidders made bids that were on average between $31 \%$ and $61 \%$ less than bidders that won comparable licenses in open bidding. In Auctions 35 and 58, where bidding credits were only available in open bidding, bidding credits still reduced revenues by $2 \%(\mathrm{CBO}, 2005)$.

Most importantly, closed bidding, as well as bidding credits, interfere with the basic Coasian principle that auctions allocate our limited spectrum to entities that will be able to make the most efficient use of the spectrum (Coase, 1959). By interfering with such allocations, efficiency and social welfare are reduced. We observe that $42 \%$ of all cellular license winning bids since 1997 used bidding credits, 15\% of licenses were won in closed licenses, and 10\% were won in closed licenses using bid credits. ${ }^{14}$ Overall, 47\% of all cellular licenses since 1997 were awarded to bidders receiving some type of preferential treatment.

\footnotetext{
${ }^{13}$ Ayres and Cramton (1996) suggest that overall government revenue was higher as a consequence of affirmative action bidding preferences in the 1994 regional narrowband auction, Auction 3. This was among the earlier auctions which had issues and served for narrowband purposes which we do not consider here.

${ }^{14}$ After 2000, small bidder credits were only allowed to be used in open license auctions.
} 
Evolution of spectrum values 10

\section{EMPIRICAL SPECIFICATION}

An explicit model of the value of spectrum would consider both factors impacting the supply of and demand for spectrum. For the specific auctions that we consider in this paper, demand for spectrum related to the provision of cellular services comes from the telecommunications companies which provide these services. These companies will consider both the efficiency and infrastructure costs associated with the provision of cellular services in each geographic market (in terms of geography, density, existing infrastructure, etc.), in a particular frequency (with different propagation and interference traits and different costs to provision of services), and with particular traits/regulations (bandwidth, risk of interference, encumbrance issues, sharing requirements, buildout requirements, etc.). Demand from these companies will also depend crucially on demand for cellular services in each geographic market (based on population, income, etc.).

In reduced form, we consider the following general expression for each license $i$ at time $t$ :

$$
\begin{aligned}
P_{i t}=\alpha+\vec{\beta}_{i} & { }_{\text {MarketTralts }_{i t}}+\vec{\lambda}_{i t}{\overrightarrow{\text { LlcenseCharacteristlcs }_{i t}}}+\gamma_{i t} \text { AuctionSize }_{i t}+\gamma_{t} \text { Spectrum Efficiency }_{t}+\epsilon_{i t}
\end{aligned}
$$

Market specific traits include population, population density, real median income, and other factors of demand for cellular services - proxied by broadband download speeds. License specific traits that we can consider are frequency, bandwidth, bandwidth squared, paired vs. unpaired frequencies, national licenses, reserve prices, constraints on participation in auction (either through open vs. closed bidding or through bidding credits in open auctions), buildout requirements, license duration, and resale requirements. Many license specific traits are collinear and some have very little variation across observations. ${ }^{15}$ Hence, we focus on a subsection of these license specific traits in our results. One license specific trait that we are not able to incorporate is possible geographic complementarities across licenses which is both

\footnotetext{
${ }^{15}$ No national licenses were offered in the auctions included in our results.
} 


\section{Evolution of spectrum values 11}

theoretically and empirically relevant (Ausubel et al., 1997; Fox and Bajari, 2013; Moreton and Spiller, 1998). This leaves open the possibility of omitted variability bias leading to higher coefficient estimates for included variables that might be positively correlated with such complementarities.

The single auction trait included in our benchmark model is the amount of new spectrum being offered in that auction. This is determined by the FCC and for our purposes can reasonably be considered as exogenous. The fact that more spectrum is being made available for cellular use could increase supply, thereby lowering winning bids. Conversely, particularly large auctions may offer greater strategic opportunities, thereby increasing winning bids.

While the amount of spectrum overall is finite and the amount of spectrum offered in any given auction is fixed and exogenous, the efficiency with which companies are able use this

spectrum is increasing over time. Such technological improvements can be thought of as easing the scarcity of our finite spectrum by increasing the "effective supply" of spectrum whether previously allocated or not.

There is endogenous pressure on regulatory authorities to make more spectrum available for private use and on firms to improve the efficiency with which they use spectrum. Still, from the perspective of an individual auction, these factors can be considered predetermined at the time of the auction. We therefore take the current state of technology, infrastructure, and demand as given and exogenous to the price outcomes of individual auctions.

FCC auctions have minimum bids for individual licenses (and at times reserve prices for blocks), which can result in a left censoring of the auction data if unsold licenses are included in the regressions. If the FCC sets the minimum bid higher than the highest private valuation for a license, then no one will bid on this license and the winning bid would be listed as zero. This would represent a left censoring of the data. However, upon closer inspection of the data sets available, we observe that most unsold licenses are simply not recorded in these data sets. An auction-by-auction comparison of licenses offered and licenses sold from 1997 to 2015 shows that $5.5 \%$ or 449 of the 8,137 licenses remained unsold at the end of the auction in which they were originally listed. Only a small subset of these unsold licenses are reported in the DotEcon 
Evolution of spectrum values 12

and Penn State Data sets which we have used as the starting point of our data set. Attempting to identify and collect data on all the unsold licenses will require going back to FCC auction-byauction data. We leave that for future research. Hence, only sold licenses are included in our regressions. This implies that we have a left truncation of our data, but not a left censoring of our data.

Low levels of competition in an auction can lead to the right censoring of true firm valuations. It is generally the case in an auction that more competition, as evidenced by a larger number of bidders, will force all bidders to bid closer to their valuations (Vickrey, 1961). If there is little competition for a license, a participating firm will lower its bid relative to its true valuation. In that case, winning bids in lower competition situations can be thought of as right censored versions of true firm valuations. If a firm faces no other competition for a license, it will bid the minimal admissible amount. Thus, bids that are equal to the license reserve price (here the minimum bid) likely represent a form of censored data; we know that the bidder's true valuation of the spectrum is greater than or equal to the reserve price, but not by how much. Just as unsold licenses represent left truncated data, licenses that sell at the reserve price are likely to be right censored data. ${ }^{16}$ The Tobit model provides a consistent estimator in the case of censored data and is theoretically preferable to OLS. We present results using both estimation techniques.

\section{PREVIOUS EMPIRICAL FINDINGS IN THE LITERATURE}

We review existing empirical findings on the significance of certain factors in spectrum valuation. This discussion is organized in groups related to license specific traits, market specific traits, and aggregate market traits.

\section{IV.A. License Specific Traits}

Frequencies:

\footnotetext{
${ }^{16}$ Our full data set consists of 7,485 observations, of which 790 (approximately 10.5 percent) sold exactly at the reserve price.
} 
Evolution of spectrum values 13

Radio frequency is a crucial determinant of spectrum value. Lower frequencies allow a signal to transmit farther distances, theoretically requiring a smaller number of overall stations to carry data across the same distance as higher frequencies (Kerans et al., 2011). Additionally, lower band spectrum benefits from lower attenuation, meaning signals are less disrupted when encountering obstacles such as buildings and landmarks, constituting an additional property which increases its range. Thus, lower frequencies require fewer cell sites and smaller infrastructure costs (Randolph, 2011; ITU, 2012; Marks et al, 2009). ${ }^{17}$ Because low frequency spectrum is more cost effective, it should attract higher premiums. Kerans et al. (2011) identify trend-lines based on previous spectrum auctions in Australia, Sweden and the U.S. stretching from 1998 to 2008. They conclude that the predicted cost of spectrum increases exponentially as frequency decreases. Wallsten (2013) similarly finds that “... spectrum below $1 \mathrm{GHz}$ is, all else equal, more valuable than spectrum above $1 \mathrm{GHz} . " 18$

We therefore use indicator variables to control for license frequencies, as well as the interaction of higher frequencies with the introduction of Multiple-Input Multiple-Output (MIMO) stations in 2009. ${ }^{19} \mathrm{We}$ assign frequencies into three buckets. Frequencies below $1 \mathrm{GHz}$ are defined as low-band, frequencies between $1 \mathrm{GHz}$ and $2 \mathrm{GHz}$ are middle-band, and frequencies above $2 \mathrm{GHz}$ are high-band. These bands were chosen both because of prevailing concepts about mobile spectrum and to insure adequate numbers of observations across the three frequency buckets. ${ }^{20}$ We later discuss how technological changes are impacting the relative value of different frequencies.

Bandwidth:

\footnotetext{
${ }^{17}$ In 2012, the ITU stated “...the minimum provision of service over a low population density region will require twice the number of base stations at $1 \mathrm{GHz}$ than at $700 \mathrm{MHz}$, eight times more at $2 \mathrm{GHz}$ and 14 times more at 2.6 GHz," p. 8.

${ }^{18}$ Wallsten (2013), p. 20.

${ }^{19}$ MIMO technology allowed for greater spectral efficiency in higher frequencies.

${ }^{20}$ These frequency buckets also tend to align with the PCS vs AWS designations (although not perfectly) and hence could also be considered in that fashion. We thank David Salant for this insight.
} 
Evolution of spectrum values 14

Theory suggests that the size of bandwidth offered in a license matters. If bandwidth sizes are too small, network performance can deteriorate because of rising congestion (Randolph, 2011). Certain technologies may also require minimum bandwidths. Hence narrowband licenses should exhibit lower intrinsic values all else equal. ${ }^{21}$ Still, beyond a certain size, additional bandwidth should have less marginal value. For this reason, we consider both bandwidth and bandwidth squared in our regressions.

\section{License Specific Rules:}

Some license specific rules have been included in past empirical work. Looking at nonU.S. data, Bohlin et al. (2010) include information about the award date, required minimum bid price, the competitiveness of the process, and various post-award obligations imposed on winners. ${ }^{22}$ Looking at U.S. auctions, Wallsten (2013) specifies whether the license is national, whether the spectrum is paired, the size of the bandwidth, its allowed use, as well as the flexibility of its permitted uses. ${ }^{23}$ Bohlin et al. (2010) find that licenses which did not originally sell but were revised and re-offered in a later auction, and higher reserve bid prices both appear to increase valuations, while more stringent post-award obligations decrease valuations.

We hope to highlight the impact of different license specific rules on auction outcomes. FCC regulations can impose significant restrictions on both the auctions mechanism (for example when incumbents are not allowed to participate in the auction for a given license) and on the inherent value of the licenses being auctioned (for example by imposing open platform

\footnotetext{
${ }^{21}$ Wallsten (2013) finds that more bandwidth diminishes private valuations, attributing it either to omitted variable bias, or to the additional time it may require to earn returns on larger spectrum bandwidths. Nonetheless, he notes that this result contradicts consensus.

22 Bohlin et al. (2010) use data from a total of 23 auctions across 21 countries for a total of only 83 observations. Since there is on average only data from one auction per country, country dummies would essentially amount to auction dummies and vice-versa. Bohlin et al. end up using a dummy variable for countries in Asia, but are thus limited by their data from controlling for distinct national markets.

${ }^{23}$ Wallsten (2013) determines 'use' based on the radiofrequency tags assigned by the FCC on each license. These include: broadband; fixed wireless; mobile radio; personal use; paging; phone; radar; radio; safety; satellite; and television. His model uses dummies for broadband, fixed wireless, mobile radio, telephone use, safety of life, television, and paging, as well as for different radio service codes (i.e. Narrowband PCS, AWS, Specialized Mobile Radio, etc.). He also includes a variable named 'flexibility' based on the number of use tags for each license. This variable ranges from 1-5 in his data.
} 
Evolution of spectrum values 15

rules). Thus, estimates of spectrum value derived from auction data must not only consider underlying market supply and demand, but also auction and license specific requirements which may shift winning bids from intrinsic market values. For these reasons, we include license specific dummies for closed licenses (not closed blocks), for licenses where the winning bidder used a bidding credit, and for the open platform requirement imposed on licenses in the $\mathrm{C}$ Block of Auction 73. Previous empirical work could at best identify closed blocks, as the data by license had not been catalogued. We have gone through each auction to correctly identify all licenses which were offered in a closed setting. Importantly, the implied impact of the closed license set asides changes when these are correctly measured at the license level.

\section{B. Market Specific Traits}

Licenses with larger populations and population densities will bring in larger revenues, increasing their value (Wallsten, 2013; Randolph, 2011; ITU, 2012; Dippon, 2009; Marks et. al., 2009; Ford, 2008; Ausubel et al., 1997). Large populations can have additional agglomeration effects since larger populations generate more economic activity (Wallsten, 2013; Strange, 2008; Ciccone and Hall, 1996; Martin et al., 2014; Fujita et al., 1999; Fujita and Thisse, 2002).

Relative to prior literature, we add two market specific measures. These include real median income for the population covered by a license, as well a measure of market specific telecommunications infrastructure (namely broadband download speeds) to proxy for variation across markets in demand for cellular services.

Companies value licenses more if they can build large contiguous geographic areas. When providers buy licenses in geographically adjacent markets, their customer base may travel through larger areas with seamless roaming, while avoiding boundary interference between different license areas (Ausubel et al., 1997). Consumers themselves have strong preferences for nation-wide coverage as opposed to regional coverage, suggesting that companies can increase revenues by buying adjacent licenses (Bajari et al., 2008). For these reasons, companies place premiums on licenses adjacent to other licenses that they've already won. This intuition is empirically supported across the literature (Ausubel et al., 1997; Fox and Bajari, 2013; Moreton 
Evolution of spectrum values 16

and Spiller, 1998). ${ }^{24}$ It is unfortunately beyond the scope of our current data set to effectively control for these regional complementarities.

\section{C. Aggregate Market Traits}

Most models try accounting for the broader environment in which these auctions operate. For example, Wallsten (2013) finds that greater aggregate policy uncertainty decreases valuations. Bohlin et al. (2010) use the average winning bid price as a proxy for national economic conditions. Dippon (2009) controls for national economic conditions by including GDP, employment percentage, and median family income. ${ }^{25}$ We follow Hazlett (2008) and use the NASDAQ index to reflect investor "... sentiment toward risky assets in the technology sector and therefore reflects economy-wide discount rates as well as expectations about the risk and growth of wireless assets." ${ }^{26}$

We further attempt to control for the general state of technology over time since this has greatly increased the potential value of higher band spectrum. ${ }^{27}$ Erik Prusch, CEO of Clearwire, remarked in an interview, "2.5 GHz, high-band, spectrum actually has an advantage over lowband spectrum in dense urban markets because it can carry much more data at higher rates. ${ }^{.28}$ Furthermore, technological improvements such as $3 \mathrm{G}$ and LTE complement higher-band spectrum, as does more advanced telecommunication technology such as Multiple-Input Multiple-Output (MIMO) stations first introduced in 2009. In fact, MIMO technology requires higher frequency (greater than $1 \mathrm{GHz}$ ) spectrum; otherwise, “...isolation becomes an issue and

\footnotetext{
${ }^{24}$ Ausbel et al. (1997) consider the first two U.S. Broadband PCS auctions, Auctions 4 and 5, which ended in 1995 and 1996 respectively. Because of issues raised with early auctions, we do not include Auctions 4 and 5 in our empirical analysis.

25 Dippon (2009) has 2300 observations collected from the 2006 U.S. AWS auction, the 2008 U.S. $700 \mathrm{MHz}$ auction, the 2007 Norwegian $2.6 \mathrm{GHz}$ auction, and the 2007 Swedish $2.6 \mathrm{GHz}$ auction.

${ }^{26}$ Hazlett (2008), p. 571.

${ }^{27}$ Wallsten (2013) includes time fixed effects to capture the effects of technological change. As previously noted, a disadvantage of using time fixed effects when considering only auctions related to cellular services is that frequently only one such auction occurs in a given year. Consequently, time fixed effects in our setting would be difficult to disentangle from auction fixed effects.

${ }^{28}$ Bennett (2014), p. 1.
} 


\section{Evolution of spectrum values 17}

the correlation between the radiation pattern is high, limiting the MIMO performance." 29 MIMO dramatically reduces the number of base stations needed at these higher frequencies, increasing spectral efficiency (Kerans et al., 2011). For these reasons, we include a measure of spectral efficiency over time, as well as control for the impact of the introduction of MIMO technology in 2009 on the relative value of higher frequency spectrum.

\section{DATA}

Like Wallsten (2013), we consider post 1996 auctions due to various recognized problems with the outcomes of the earliest auctions (Kwerel and Rosston, 2000; Wallsten, 2013). Unlike Wallsten, rather than include all auctions, we focus on a narrower market, namely the market for spectrum related to the provision of cellular services, and control for market specific telecommunications infrastructure to proxy for variation across markets in demand for cellular services. ${ }^{30}$ Our analysis therefore includes all successfully auctioned FCC licenses related to the provision of mobile services from 1997 to 2015. Table 1 presents the list of these auctions, including their frequencies, designated uses, number of licenses offered, percent of licenses sold, and average headline price per $\mathrm{MHz}$ per population. ${ }^{31}$

The starting point for our spectrum auction dataset comes from the economic consulting firm DotEcon. The DotEcon dataset contains license level data for each license in over 30 countries, of which the largest subset proportion are U.S. licenses. In this paper, we focus on the

\footnotetext{
${ }^{29}$ Varrall (2012), p. 153.

30 Wallsten (2013) includes most FCC auctions between 1996 and 2011 for a total of over 63,000 observations. This includes licenses used in mobile applications, television broadcasting, telemetry, and a diverse range of wireless services. Wallsten controls for different 'use' through radio frequency tags. However, these tags can at times be imprecise. For example, the $700 \mathrm{MHz}$ band is frequently used for LTE, but has tags for mobile radio, phone, fixed wireless, broadband, and TV. Similarly, Auction 17 was tagged for the provision of broadband services, but its frequency range (27.5-31.3 GHz) is used for video programming distribution--not cellular services. Both of these examples would be identified as broadband using radio frequency tags, despite their uses being different in nature.

${ }^{31}$ Our full data set further includes data from Narrowband auctions $(41,50$, and 51) and from auctions in very high frequencies $(17,23$, and 56). These licenses are for fundamentally different services and so are not included in the results presented here. Still the data from those additional auctions are included in the data set which we have made public.
} 


\section{Evolution of spectrum values 18}

Table 1. Summary of FCC Auctions Included Analysis

\begin{tabular}{|c|c|c|c|c|c|c|c|c|c|c|}
\hline Auction & Year $^{1}$ & $\begin{array}{l}\text { Frequency } \\
\text { Range } \\
(\mathrm{MHz})^{2}\end{array}$ & $\begin{array}{c}\text { License } \\
\text { Bandwidth } \\
(\mathrm{MHz})\end{array}$ & $\begin{array}{l}\text { Specified } \\
\text { Use }^{3}\end{array}$ & $\begin{array}{c}\text { \# of } \\
\text { Licenses }\end{array}$ & $\begin{array}{c}\% \\
\text { Unsold }\end{array}$ & $\begin{array}{c}\% \\
\text { Paired }\end{array}$ & $\begin{array}{l}\text { Dollars per } \\
\text { MHz Pop }^{4}\end{array}$ & $\begin{array}{c}\text { Gross } \\
\text { Winning } \text { Bid }^{4}\end{array}$ & $\begin{array}{l}\text { \# of } \\
\text { Obs. }\end{array}$ \\
\hline 11 & 1997 & $1865-1975$ & 10 & $\begin{array}{c}\text { BB; FW; } \\
\text { MR; Phone }\end{array}$ & 1479 & 0.47 & 100 & 0.32 & $\begin{array}{c}2,962,939,39 \\
2\end{array}$ & 1454 \\
\hline 22 & 1999 & $1885-1990$ & 23.77 & $\begin{array}{c}\text { BB; FW; } \\
\text { MR; Phone }\end{array}$ & 347 & 12.96 & 100 & 0.13 & $558,671,040$ & 293 \\
\hline 33 & 2000 & $746-794$ & 2.96 & $\begin{array}{c}\text { BB; FW; } \\
\text { MR; Phone; } \\
\text { TV }\end{array}$ & 104 & 7.69 & 100 & 0.34 & $546,828,352$ & 90 \\
\hline $35^{5}$ & 2001 & 1890-1990 & 10.51 & $\begin{array}{l}\text { BB; FW; } \\
\text { MR; Phone }\end{array}$ & 422 & 0.00 & 100 & 2.11 & $\begin{array}{c}17,426,655,2 \\
32\end{array}$ & 420 \\
\hline 38 & 2001 & $746-794$ & 3.67 & $\begin{array}{l}\text { BB; FW; } \\
\text { MR; Phone } \\
\text { TV }\end{array}$ & 8 & 0.00 & 100 & 0.52 & $23,765,016$ & 6 \\
\hline 44 & 2002 & $710-746$ & 11.98 & $\begin{array}{l}\text { BB; FW; } \\
\text { MR; Phone; } \\
\text { TV }\end{array}$ & 740 & 34.59 & 99.8 & 0.04 & $111,687,272$ & 480 \\
\hline 49 & 2003 & $710-746$ & 11.87 & $\begin{array}{l}\text { BB; FW; } \\
\text { MR; Phone; } \\
\text { TV }\end{array}$ & 256 & 1.95 & 97.9 & 0.03 & $59,818,464$ & 242 \\
\hline 58 & 2005 & $1850-1990$ & 10.27 & $\begin{array}{c}\text { BB; FW; } \\
\text { MR; Phone }\end{array}$ & 242 & 10.33 & 100 & 0.54 & $\begin{array}{c}2,037,090,30 \\
4\end{array}$ & 215 \\
\hline 66 & 2006 & $1710-2155$ & 18.25 & $\begin{array}{l}\text { BB; FW; } \\
\text { Phone }\end{array}$ & 1122 & 3.12 & 100 & 0.17 & $\begin{array}{c}11,901,267,9 \\
68 \\
\end{array}$ & 1069 \\
\hline 71 & 2007 & $1850-1990$ & 10.36 & $\begin{array}{c}\text { BB; FW; } \\
\text { MR; Phone }\end{array}$ & 38 & 13.16 & 100 & 0.22 & $12,247,984$ & 28 \\
\hline $73^{6}$ & 2008 & $698-806$ & 11.13 & $\begin{array}{l}\text { BB; FW; } \\
\text { MR; Phone; } \\
\text { TV }\end{array}$ & 1099 & 0.82 & 83.8 & 0.73 & $\begin{array}{c}15,577,722,8 \\
80\end{array}$ & 1063 \\
\hline 78 & 2008 & $\begin{array}{l}\frac{\text { AWS-1: }}{1710-2155} \\
\underline{\text { BB PCS: }} \\
1865-1990\end{array}$ & 15.17 & $\begin{array}{l}\text { AWS-1: } \\
\text { BB; FW; } \\
\text { MR; Phone; } \\
\text { BB PCS: } \\
\text { BB; FW; } \\
\text { MR; Phone }\end{array}$ & 55 & 3.64 & 100 & $\begin{array}{l}\frac{\text { AWS-1: }}{0.10} \\
\frac{\text { BB PCS: }}{0.19}\end{array}$ & $18,738,642$ & 29 \\
\hline 92 & 2011 & $698-806$ & 12 & $\begin{array}{c}\text { BB; FW; } \\
\text { MR; Phone } \\
\text { TV }\end{array}$ & 16 & 0.00 & 100 & 0.39 & $15,739,168$ & 9 \\
\hline 96 & 2014 & $1915-2000$ & 10 & $\begin{array}{l}\text { BB; FW; } \\
\text { Phone }\end{array}$ & 176 & 0.00 & 100 & 0.29 & $\begin{array}{c}1,155,609,34 \\
4\end{array}$ & 172 \\
\hline 97 & 2015 & $1695-2180$ & 10.55 & $\begin{array}{l}\text { BB; FW; } \\
\text { Phone }\end{array}$ & 1614 & 0.19 & 78.2 & 0.68 & $\begin{array}{c}33,045,043,2 \\
00\end{array}$ & 1573 \\
\hline
\end{tabular}

${ }^{1}$ Year in which the auction ended ${ }^{2}$ Not always continuous ${ }^{3} \mathrm{BB}=$ Broadband, FW=Fixed Wireless, MR=Mobile Radio ${ }^{4}$ Constant 2000 dollars

${ }^{5}$ Closed auction rules changed ${ }^{6}$ Anonymous bidding introduced 
Evolution of spectrum values 19

U.S. data. The DotEcon dataset includes information on the date of the auction, license duration, winner's identity, population covered, frequency range, reserve price, headline price, etc. ${ }^{32}$ Since we focus on spectrum applied to cellular communications (phone, broadband, mobile radio, etc.) and not including other purposes such as paging, we consider only auctions which include licenses for cellular communication. There are 15 such auctions between 1997 and 2015. The DotEcon dataset does not include the most recent auctions, so we added data on auctions 92, 96 and 97 collected directly from the FCC website.

The Center for the Study of Auctions, Procurements and Competition Policy at Pennsylvania State University provides data for FCC auctions up to Auction 82 in 2002. The Penn State dataset includes similar variables as those of the DotEcon dataset, but does not include international data. Like DotEcon, the Penn State dataset contains data on some, but not all, unsold licenses. The Penn State dataset additionally allows for a review of round by round results. Connolly, Zrenner, and Nnoromele (2017) use Penn State round level data to measure the number of bidders active in the auction of each license. As an extension to our benchmark model, we use this measure to reflect the level of competition within the auction for each license. ${ }^{33}$

We add key variables to previous FCC auctions data sets. Specifically, we

1. add FCC data on Auctions 92, 96 and 97,

2. identify individual blocks within each auction,

3. collect license specific auction rules data including closed auctions, resale restrictions, buildout requirements, duration of license, and sharing requirements,

4. identify winning bids which used bid credits,

5. add income and geographic data by market and date,

6. add broadband upload and download speeds data by market and date,

\footnotetext{
32 We have noticed some problems with the reserve price data from DotEcon and therefore do not include it in our analysis.

${ }^{33}$ While the number of active bidders in a license auction is influenced by other license and market specific traits, this proxy for the level of competition in the auction itself is important both in terms of the likelihood that auction outcomes are closer to reflecting true valuations and in terms of capturing the impact of potential omitted variables on the desirability of a particular license.
} 
Evolution of spectrum values 20

7. add measures of spectral efficiency over time, and

8. add the number of bidders active in the auction for a specific license.

We explain each in turn.

1. Auctions 92, 96 and 97 data come directly from the FCC online auction results.

2. Auction Blocks:

Within each auction, the FCC assigns licenses to different blocks, each block specifying its own auction rules within a given auction. ${ }^{34}$ These rules vary and include such things as firm eligibility to bid, bidding credits (discounts), platform sharing requirements, payment requirements, build-out requirements, license duration, and other factors. Block names vary from auction to auction, but are most often labeled A, B, C, and so on. Rules for a given block, like block $\mathrm{B}$, generally change from auction to auction, although some block names are associated with certain types of recurring rules. For example, $\mathrm{C}$ and $\mathrm{F}$ blocks are blocks that are generally set aside for small bidders. Still, the definition of a small bidder has changed from auction to auction, as have the specific set-asides within these blocks.

3. License, Block, and Auction Rules:

Connolly et al. (2017a) catalogue license, block, and auction specific rules. Some auction rules (such as license duration and paired-bands) are already available in existing datasets. However, much block specific information and almost all license specific information had not been previously brought together into a single data set. To achieve this, we collected data from each auction individually. Among the data we collected are "Small" and "Very Small Bidder" designations (which have changed over time), identifying closed licenses (since some licenses in Closed Blocks were offered in open bidding after 2000), build out requirements (by block and auction), resale restrictions, down payment information, payoff information, open platform rules, sharing requirements, auction mechanism, etc. From these we have selected key rules which offer enough variation across licenses and time to be of value in our analysis. ${ }^{35}$

\footnotetext{
${ }^{34}$ We describe how we identify auction blocks in Section A2 of the Appendix.

${ }^{35}$ For example, we do not use license duration in our regressions as there is both little variation in duration across the licenses and the presumption of license renewal is strong in the U.S., making the specific length of the initial
} 
Evolution of spectrum values 21

\section{Bidding Credits}

The FCC offers discounts to small bidders to help them compete with larger companies, like Verizon and AT\&T. For auctions 66, 71, 73, 78, 92, 96, and 97 the FCC's "Provisionary Winning Bid Report" includes the auction number, the lot name, the provisionary winning bid, and the net winning bid, i.e. the amount the winner paid after any discount. For auctions before auction 66, we collected the data from auction specific FCC reports.

5. Demographic Data by Market

Population is provided in most existing auction data sets. Using annual county level median income data from the Census Bureau's SAIPES, as well as county area information from the FCC, we construct total area and annual median income measures for every FCC region in the continental United States, Alaska, and Hawaii. To construct the annual median income measures from county level median income data we weight the median average by the 2000 census population for each county. This combined dataset is then matched with each license by region. We convert all nominal data into 2000 dollars using the monthly US CPI estimates from the National Bureau of Economic Research (NBER).

6. Broadband Speeds: Proxy for Market Infrastructure

The auction data from DotEcon include the variable region, which gives the area covered by the spectrum for that license. From OOKLA, a company specializing in broadband testing, we have separate monthly data on broadband upload and download speeds in various cities in the United States starting in 2008 (OOKLA.com). These speeds serve as a proxy for existing communications infrastructure by market. Namely, a city with fast broadband likely also has significant existing infrastructure for cellular data transmission, reducing the investment necessary for a cellular company to fully utilize the spectrum. ${ }^{36}$

license less relevant. Similarly, over time the FCC has made some modifications to its auction mechanism, such as including package bidding in later auctions. Only three main auction mechanisms have been used to date, and since our focus is on spectrum value versus auction design, we do not include this variable. Still, we hope that the overall data set created in Connolly et al. (2017a) will be of value to future researchers investigating other dimensions of FCC spectrum auctions.

${ }^{36}$ A full description of how we merged these data sets is provided in the section A2 of the appendix. 
Evolution of spectrum values 22

Figure 1. Broadband Download Speeds for Select Cities (2008-2015)

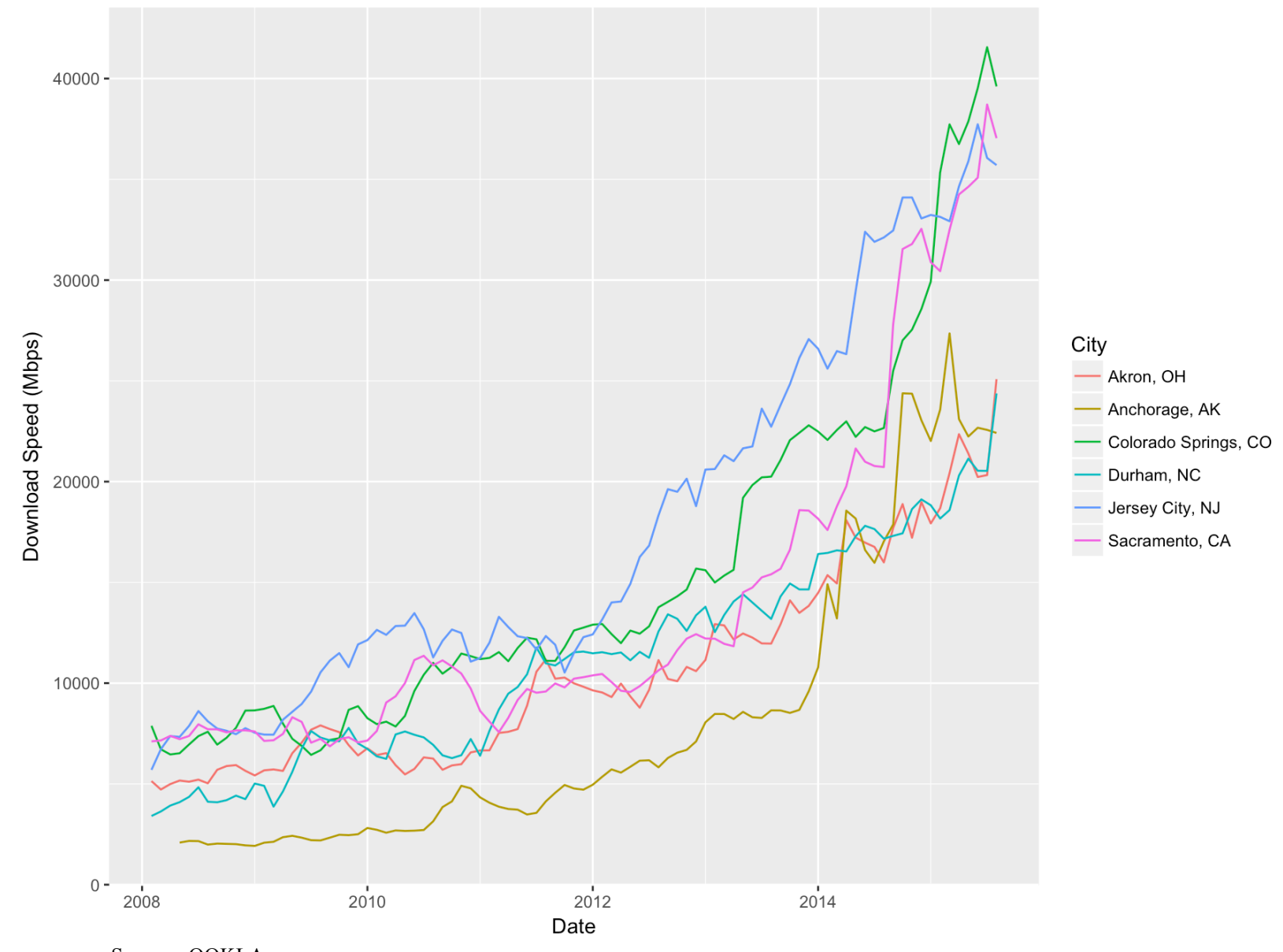

Source: OOKLA

The broadband speed data include multiple observations over time for most locations. For each auction, we select the monthly broadband data observation which is closest to the auction date. Our earliest broadband speed observation is for 2008 , so we restrict our matches to those auctions that occurred in 2007 or later. Auctions occurring before 2006 are too distant to be related to the observed data. Figures 1 and 2 respectively show download and upload speeds over time for randomly selected cities in the United States.

The overall trend in download speeds over time looks similar across cities. The speeds in Anchorage, AK begin below average but rise to match the other cities over the period in question. The trends for upload speeds are less uniform. The upload speeds in Jersey City have 
Evolution of spectrum values 23

grown much more quickly over the period. In addition, Anchorage does not begin with the slowest speeds, although it is consistently among the slowest cities.

\section{Figure 2. Fixed Broadband Upload Speeds for Select Cities (2008-2015)}

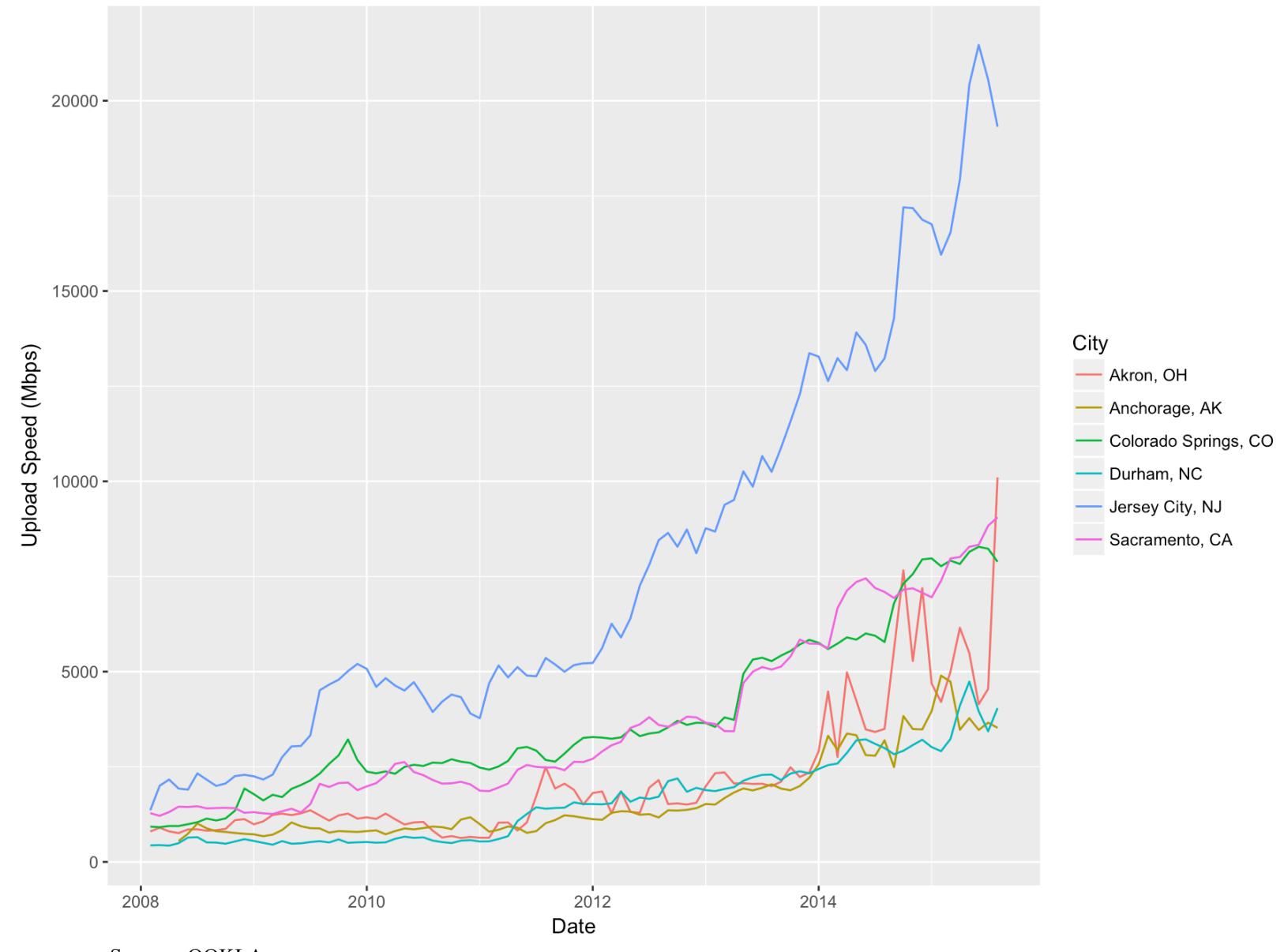

Figure 3 shows the density estimates for download speeds in various years. More recent years are shown in lighter shades of blue. The figure demonstrates that in 2008 many cities had very slow download, as seen by the large dark peak on the left-hand side. Over time, greater variability appears in the download speeds (seen by the decreasing height of the densities) and the median speed increases (as seen by the shift to the right). By 2015 we see much faster download and greater variability in download speeds than in 2008. 
Evolution of spectrum values 24

Figure 3. Broadband Download Speeds (2008 - 2015)

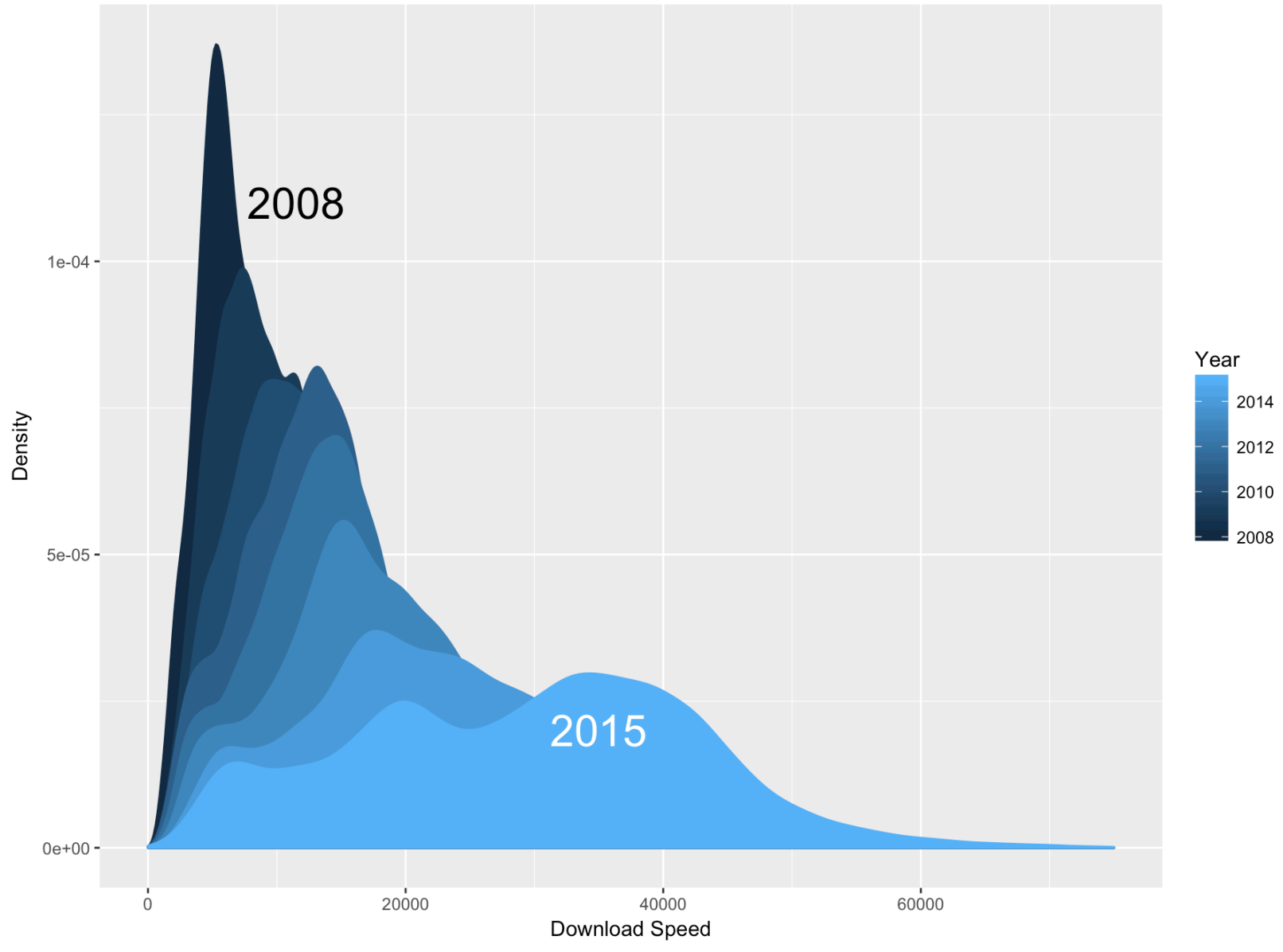

Source: OOKLA

\section{Spectral Efficiency}

Rumney (2007 and 2009) suggests four potential measures of spectral efficiency over time: maximum net bitrate, bandwidth, maximum link spectral efficiency, and system spectral efficiency. Bitrate measures the speed of data transmission, or the amount of information transmitted over a given period. While the gross bitrate includes the total amount of information transmitted, including error correction codes and other extraneous information, the net bitrate only measures the information in the original message. The third measure, link spectral efficiency, is calculated by dividing net bitrate by the bandwidth each technology occupies. Finally, system spectral efficiency is spectral efficiency per site, calculated by dividing link 
Evolution of spectrum values 25

spectral efficiency by the number of cellular towers (and other related infrastructure) required. System spectral efficiency appears to be the most useful measure for our purposes since it accounts for the fact that different generations of technologies require different levels of investments in infrastructure. ${ }^{37}$

Figure 4. Spectral Efficiency Per Site ((bit/s)/Hz per site) from 1991 to 2013

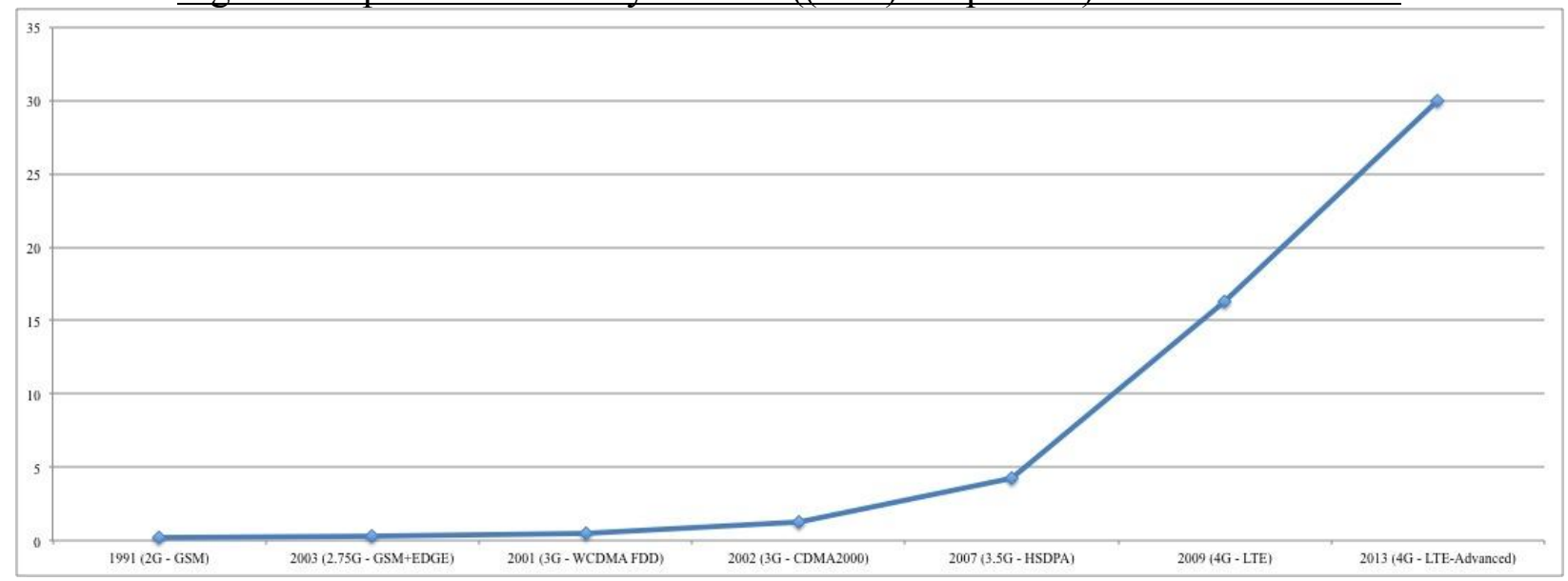

\section{RESULTS}

Headline prices, population, population density and real median income are all heavily skewed in our data. We therefore take the natural log of these variables to yield more symmetric and unimodal distributions. We undertake both OLS and Tobit regressions to get a sense of how important controlling for censored data is in this analysis. The OLS and Tobit results seem generally consistent, suggesting that this may not be too big of a problem in our data set. Table 2 presents the results from the OLS regressions. Results from the parallel Tobit regressions are presented in the appendix in Table $3 \mathrm{~A}$.

The first two columns of Table 2 include cellular auctions from 1997 to 2015, for a total of over 7,000 observations. The last two columns include only the more recent 2007 to 2015 auctions with around 2,900 observations. This later time period allows us to include fixed broadband download speeds by market as a proxy for the general level of communications

37 The link spectral efficiencies we use are all based on SISO (Single Input Single Output) since MIMO (Multiple Input Multiple Output) is a newer technology which did not appear before 4G. 
Evolution of spectrum values 26

infrastructure in that market. These data only cover a portion of the markets in our auction data and hence drops the number of observations to $2,080 .{ }^{38}$

Columns 1 and 3 present the benchmark model for 1997-2015 and for 2007-2015, respectively. Columns 2 and 4 further control for the number of bidders active over all rounds for each license, as well as that number squared. These are not included in the benchmark model since the number of participants in an auction should likely increase with the overall value of a license. While we control for most variables that should impact license value, there is always a risk of there being an omitted variable, whose effect might be captured by the number of bidders for that license. For this reason, we first present benchmarks in columns 1 and 3 without bidder numbers. However, in columns 2 and 4 we add the number of bidders active in a license auction to capture the effect of greater competition within an auction on winning bids. We further include the square of the number of bidders active in the license auction to reflect the non-linear impact on winning bids as the number of bidders increases since the winning bid will be pushed towards the highest true valuation pretty quickly as the number of bidders increases.

\section{License}

Bandwidth

The larger the bandwidth for a license, the more spectrum is available to the license holder. A larger band can carry more information with less concern about interference, which should increase the value. Indeed, the bandwidth coefficients are all positive. Still this effect should level out as confirmed by the negative coefficients for bandwidth squared.

\section{Paired Bands}

A license with a paired band consists of two separate bands, one of which can be used for sending signals while the other is used to receive signals. The usefulness of paired spectrum

\footnotetext{
38 To test for possible self-selection bias in the markets for which broadband speeds are recorded, we compare regression results for 2007-2014 with and without the broadband download speeds. The results are highly consistent, suggesting not too great an effect from possible self-selection.
} 


\section{Evolution of spectrum values 27}

Table 2. Log Real Headline Price - OLS Regressions

\begin{tabular}{|c|c|c|c|c|}
\hline & \multicolumn{2}{|c|}{$1997-2015$} & \multicolumn{2}{|c|}{$2007-2015$} \\
\hline License & 1 & 2 & 3 & 4 \\
\hline License Bandwidth & $\begin{array}{c}0.481 \\
(32.07)\end{array}$ & $\begin{array}{c}0.478 \\
(34.68)\end{array}$ & $\begin{array}{c}0.622 \\
(20.00)\end{array}$ & $\begin{array}{c}0.579 \\
(18.50)\end{array}$ \\
\hline License Bandwidth Squared & $\begin{array}{l}-0.0133 \\
(-31.06)\end{array}$ & $\begin{array}{l}-0.0121 \\
(-30.38)\end{array}$ & $\begin{array}{l}-0.0189 \\
(-17.13)\end{array}$ & $\begin{array}{l}-0.0171 \\
(-15.36)\end{array}$ \\
\hline Paired Band & $\begin{array}{l}0.656 \\
(6.99)\end{array}$ & $\begin{array}{l}0.261 \\
(3.00)\end{array}$ & $\begin{array}{l}0.265 \\
(2.67)\end{array}$ & $\begin{array}{l}0.249 \\
(2.53)\end{array}$ \\
\hline $\begin{array}{r}\text { Frequencies between } \\
1000 \text { and } 2000 \mathrm{MHz}\end{array}$ & $\begin{array}{l}0.230 \\
(6.15)\end{array}$ & $\begin{array}{l}0.0217 \\
(0.62)\end{array}$ & $\begin{array}{c}0.181 \\
(1.18)\end{array}$ & $\begin{array}{l}0.119 \\
(0.78)\end{array}$ \\
\hline $\begin{array}{r}\text { Frequencies above } \\
2000 \mathrm{MHz}\end{array}$ & $\begin{array}{l}-2.095 \\
(-33.09)\end{array}$ & $\begin{array}{l}-1.622 \\
(-27.21)\end{array}$ & $\begin{array}{l}-0.148 \\
(-0.52)\end{array}$ & $\begin{array}{l}-0.279 \\
(-0.99)\end{array}$ \\
\hline High Frequency Effect after MIMO & $\begin{array}{l}2.880 \\
(22.66)\end{array}$ & $\begin{array}{c}2.325 \\
(19.76)\end{array}$ & $\begin{array}{l}1.484 \\
(4.60)\end{array}$ & $\begin{array}{l}1.444 \\
(4.54)\end{array}$ \\
\hline Closed License & $\begin{array}{l}-0.108 \\
(-2.33)\end{array}$ & $\begin{array}{l}0.000738 \\
(0.02)\end{array}$ & $\begin{array}{l}-0.246 \\
(-1.09)\end{array}$ & $\begin{array}{l}-0.312 \\
(-1.40)\end{array}$ \\
\hline $\begin{array}{r}\text { Auction } 73 \mathrm{C} \text { block licenses with } \\
\text { Open Access Requirement }\end{array}$ & $\begin{array}{l}-0.543 \\
(-1.49)\end{array}$ & $\begin{array}{l}-0.530 \\
(-1.59)\end{array}$ & - & - \\
\hline Bidding Credit Used in Winning Bid & $\begin{array}{c}-0.397 \\
(-14.23) \\
\end{array}$ & $\begin{array}{c}-0.383 \\
(-14.93) \\
\end{array}$ & $\begin{array}{c}-0.482 \\
(-11.54) \\
\end{array}$ & $\begin{array}{c}-0.506 \\
(-12.19) \\
\end{array}$ \\
\hline \multicolumn{5}{|l|}{ Market } \\
\hline Population (Logs) & $\begin{array}{c}1.253 \\
(93.71)\end{array}$ & $\begin{array}{c}1.186 \\
(95.52)\end{array}$ & $\begin{array}{l}1.198 \\
(67.27)\end{array}$ & $\begin{array}{c}1.192 \\
(67.80)\end{array}$ \\
\hline Population Density (Logs) & $\begin{array}{l}-0.0135 \\
(-1.20)\end{array}$ & $\begin{array}{c}-0.00752 \\
(-0.72)\end{array}$ & $\begin{array}{l}0.125 \\
(8.34)\end{array}$ & $\begin{array}{l}0.120 \\
(8.09)\end{array}$ \\
\hline Real Median Income (Logs) & $\begin{array}{c}0.981 \\
(13.20)\end{array}$ & $\begin{array}{c}0.876 \\
(12.82)\end{array}$ & $\begin{array}{l}1.281 \\
(12.41)\end{array}$ & $\begin{array}{c}1.187 \\
(11.60)\end{array}$ \\
\hline $\begin{array}{r}\text { Infrastructure Proxy: } \\
\text { Avg. Download speed (Mbps) in } \\
\text { License Area }\end{array}$ & & & $\begin{array}{c}0.00163 \\
(0.69)\end{array}$ & $\begin{array}{l}0.00152 \\
(0.65)\end{array}$ \\
\hline \multicolumn{5}{|l|}{ National } \\
\hline $\begin{array}{r}\text { Spectral Efficiency per Site } \\
\text { (bit/S/Hz/site) }\end{array}$ & $\begin{array}{c}-0.134 \\
(-27.48)\end{array}$ & $\begin{array}{l}-0.0932 \\
(-20.02)\end{array}$ & $\begin{array}{c}-0.0687 \\
(-8.87)\end{array}$ & $\begin{array}{l}-0.0732 \\
(-9.55)\end{array}$ \\
\hline NASDAQ & $\begin{array}{l}0.00139 \\
(45.23)\end{array}$ & $\begin{array}{c}0.000921 \\
(29.11)\end{array}$ & $\begin{array}{c}0.000301 \\
(3.72)\end{array}$ & $\begin{array}{c}0.000412 \\
(5.08)\end{array}$ \\
\hline \multicolumn{5}{|l|}{ Auction Competition } \\
\hline $\begin{array}{r}\text { Total Spectrum Offered } \\
\text { in Auction }\end{array}$ & $\begin{array}{c}0.0000729 \\
(23.58)\end{array}$ & $\begin{array}{c}0.0000411 \\
(13.59)\end{array}$ & $\begin{array}{c}0.0000694 \\
(15.36)\end{array}$ & $\begin{array}{c}0.0000574 \\
(12.16)\end{array}$ \\
\hline \# bidders for license & & $\begin{array}{c}0.434 \\
(25.45)\end{array}$ & & $\begin{array}{l}0.0986 \\
(2.99)\end{array}$ \\
\hline \# of bidders for license squared & & $\begin{array}{l}-0.0200 \\
(-14.43) \\
\end{array}$ & & $\begin{array}{c}-0.00114 \\
(-0.44)\end{array}$ \\
\hline Constant & $\begin{array}{c}-19.97 \\
(-26.27) \\
\end{array}$ & $\begin{array}{c}-17.99 \\
(-25.65) \\
\end{array}$ & $\begin{array}{c}-20.79 \\
(-19.49) \\
\end{array}$ & $\begin{array}{l}-19.96 \\
(-18.82) \\
\end{array}$ \\
\hline Observations & 7134 & 7109 & 2082 & 2080 \\
\hline Adjusted $\mathrm{R}^{2}$ & 0.784 & 0.818 & 0.878 & 0.881 \\
\hline Auctions Included & \multicolumn{2}{|c|}{$\begin{array}{c}11,22,33,35,38,44,49,58,66,71,73,78,92 \\
96,97\end{array}$} & \multicolumn{2}{|c|}{$71,73,78,92,96,97$} \\
\hline Auction Years (Start Dates) & \multicolumn{2}{|c|}{$\begin{array}{c}1997,1999,2000,2001,2002,2003,2005,2006 \\
2007,2008,2011,2014\end{array}$} & \multicolumn{2}{|c|}{$2007,2008,2011,2014$} \\
\hline
\end{tabular}


Evolution of spectrum values 28

should increase the value of a license, which is empirically confirmed in our results and is consistent with Wallsten (2013). ${ }^{39}$

\section{Frequencies}

Results are presented for our middle $(1000-2000 \mathrm{MHz})$ and high $(>2000 \mathrm{MHz})$ frequency buckets, with the lowest frequency dummy omitted from the regression. ${ }^{40}$ Hence, the coefficients on the middle and high frequency buckets are relative to the lowest frequency bucket. The coefficient for the middle frequencies is positive in the benchmark model for the full period, but is statistically insignificant in the remaining three specifications. The highest frequency bucket (above $2 \mathrm{GHz}$ ) is found to be less valuable than the low frequency bucket over the full 1997 to 2015 period. In the more recent period (2007 to 2015) however, the dummy on the high frequency bucket becomes insignificant, implying that it is no longer being discounted in auctions relative to the lowest frequency bucket.

Moreover, we are interested in the interaction between MIMO and frequencies above 2 GHz. We therefore interact the high frequency dummy with the 2009 launch of Multiple Input/Multiple Output (MIMO). This transmission technology increased the suitability of high frequency spectrum for transmitting cellular data and became more widely used around the mid to late 2000s. There is a time gap between the time when MIMO was first introduced and the time when it became widely adopted. Still, once a technology is known and its potential value is known, it should affect auction bids which consider value of spectrum over the duration of a license. Even in columns 1 and 2, where the simple coefficient on the high frequency bucket is negative, the coefficient on the MIMO interaction with the high frequency bucket after 2009 shows a combined positive coefficient for these higher frequencies after 2009. In the 2007 to 2015 period, the effect is more obvious since the coefficient on the high frequency bucket is not

\footnotetext{
${ }^{39}$ It is worth noting that over $90 \%$ of licenses in our data set are paired.

${ }^{40}$ For auctions from 1997 to 2015, there are 2,232 low frequency licenses, 2,767 mid-frequency licenses, and 2,486 high-frequency licenses.
} 
Evolution of spectrum values 29

statistically significantly different from zero, while the MIMO interaction with the high frequency bucket is positive and statistically significant. ${ }^{41}$

\section{Small Bidder Credits}

The fact that $42 \%$ of all cellular licenses were won using small bidder credits demonstrates the extremely large explicit subsidy offered by the government to firms eligible for such credits. Beyond the explicit credits however, we also see that the headline winning bids are further lowered (even before accounting for any credits) when won by a small bidder. This result is consistent across all four models and likely reflects decreased competition from nonpreferred bidders (through shaved bidding or through non-participation) in licenses where small bidders are actively participating in the auction.

\section{Closed Licenses}

In our benchmark model, closed licenses (where only small firms/entrepreneurs are allowed to participate) have statistically lower winning bids than licenses offered in open bidding in the 2007-2014 period. The closed designation for a license is however not found to be statistically significant once we control for the number of bidders active in a license auction or in the more recent 2007 to 2015 period. This suggests that the set asides have not led to sufficiently increased participation by small bidders as to offset the exclusion of non-preferred bidders. ${ }^{42}$

\section{Open Platform Requirement}

In columns 1 and 2, we see no statistically significant impact of the open platform requirement for the $\mathrm{C}$ block in Auction 73 beyond the effect on price of being in a closed block. This is somewhat surprising given concerns expressed by Crawford, Kwerel, and Levy (2008),

\footnotetext{
${ }^{41}$ The impact of MIMO estimated here is different from a simple post 2009 dummy both by definition and in our regression estimates. If we use a post 2009 dummy instead, that term has a large negative coefficient in our 2007 to 2015 regressions, while maintaining negative coefficient estimates for the high frequency bucket.

42 It is further worth noting that after 2000, fewer licenses (only 5.4\% relative to $42 \%$ of all licenses from 1997 to 2000 ) were offered as set-asides and that Tier I markets (with populations greater than or equal to 2.5 million) were less likely than smaller markets to be offered in set-aside licenses (FCC, 2000).
} 
Evolution of spectrum values 30

Ford et al. (2008) and what Brusco, Lopomo, and Marx (2009) refer to as "The Google Effect". 43 It should however be noted that there are only eight observations in our data set for which this effect is present. ${ }^{44}$

Market

Licenses with a larger population, higher population density, and higher median income should be more valuable because of greater expected profits. As expected, log population and $\log$ real median income are positive and statistically significant throughout. Log population density is statistically significant but only in the shorter 2007-2014 period.

\section{Fixed Broadband Download Speed}

The inclusion of market/license specific broadband download speed limits the time frame considered in Columns 3 and 4 because it is only available for later dates. As a proxy for the current infrastructure in a market, and consequently for higher demand for cellular services, we had expected this term to be positive and statistically significant. However, results in columns 3 and 4 do not find this variable to be statistically significantly different from zero.

National

Spectral efficiency per site, which we include to attempt to capture technological changes leading to increased efficiency of spectrum use, is negative over all four models. This is consistent with the intuition that greater effective use of spectrum increases the "effective spectrum." All else equal, such an increase in effective spectrum decreases the price of spectrum.

\footnotetext{
43 Brusco, Lopomo, and Marx (2009) explain "These licenses were initially offered subject to an open platform restriction, which was highly valued by firms such as Google. Google entered bids until its bids reached the C-block reserve price, thereby ensuring that the open platform restriction would be applied to the licenses. Later in the auction, other bidders outbid Google, so Google was able to trigger the open platform restriction without having to purchase any of the licenses." p. 101.

${ }_{44}$ Our data set does not include information on broadband speeds for the markets for the relevant $\mathrm{C}$ block licenses from Auction 73, so it is not possible to estimate this coefficient in columns 3 and 4 . The finding of a statistically insignificant coefficient on the open access requirement remains when the broadband download speed variable is omitted.
} 
Evolution of spectrum values 31

Similarly to Hazlett (2009), we find that the NASDAQ positively impacts winning bid values in all of our specifications.

\section{Auction Competition}

The total spectrum offered in an auction is the sum of the bandwidths of all licenses available in the auction. On one hand, a large auction means that more physical spectrum is being made available for private use, potentially lowering winning bids. On the other hand, auctions offering larger amounts of spectrum have a higher possibility of disrupting the status quo of a market, and may therefore push up winning bids. Specifically, if a smaller firm can acquire a large amount of spectrum, it can gain market power relative to the largest firms. In all four models, we find that total spectrum offered in an auction has a small but statistically significant impact on winning bids. This suggests that this variable is capturing a net procompetitive effect in larger auctions.

The number of active bidders in a license auction is influenced by license and market specific traits. To that extent, including the number of bidders in a license auction might create collinearity problems or might capture the effects of a possibly omitted variable. However, this proxy for the level of competition in the auction is important in terms of the likelihood that winning bids are being pushed closer to true valuations. We therefore include the number of bidders active in a license auction, as well as the number of active bidders squared, in columns 2 and 4. The squared term is included to capture the fact that auction competition (and therefore the likelihood that winning bids are closer to true valuations) likely responds non-linearly to the number of bidders active in an auction. As expected, the number of active bidders in a license auction positively impacts winning bid values but with diminishing impact.

\section{CONCLUSIONS}

This paper analyzes all FCC spectrum auctions related to cellular services from 1997 to 2015. It is the first to incorporate a range of license specific rules. These significantly impact auction results and must be considered if one is hoping to use winning auction bids to try to 
Evolution of spectrum values 32

estimate inherent spectrum value. Finally, this is also one of the first papers to go beyond a simple time trend in an attempt to disentangle the impact of various types of technological change and their impact on both spectrum scarcity and demand for spectrum. Here we have attempted to distinguish between these two types of technological advances. Moreover, on the demand side, we have controlled for market level infrastructure to better distinguish the impact of the varied adoption of certain technologies across markets.

Our results confirm previous theoretical and empirical findings such as the positive value of population, income, population density, bandwidth, and paired bands on spectrum auction results. We also find empirical evidence highlighting the negative impacts of the use of small bidder credits on license valuation, likely through anti-competitive effects. These types of rules lower winning auction values and would cause underestimation of the inherent value of spectrum should they not be controlled for in the analysis.

Incorporating market level proxies for demand for cellular services and national measures of increasing spectral efficiency which decrease spectral scarcity, allows us to gain greater insight into the technological forces influencing spectrum values over time. We find evidence that the value of higher frequency spectrum (above 2GHz) is rising over time due to technological advances relative to both mid and low frequency spectrum.

From a policy perspective, our most surprising discovery is the magnitude of the impact of preferential treatments on both the allocation and pricing of U.S. spectrum. No less than $42 \%$ of all cellular licenses from 1997 to 2014 were purchased using small bidder credits. Closed licenses have become less prevalent over time due to a change in FCC policy in 2000 but small bidder credits remain common. Overall, from 1997 to 2014, 47\% of all cellular licenses were won by bidders benefiting from one or more of these preferential treatments. Even adjusting based on auction valuation, this impacted over a quarter of the spectrum auctioned by the FCC for cellular purposes from 1997 to 2014. This has important implications in terms of lost revenue to the U.S. government both from the direct credits offered by the FCC, as well as the lowered winning bid values that we observe in this paper. It also implies that these policies are at best, reducing economic efficiency by allocating almost half of our scarce spectrum to firms 
Evolution of spectrum values 33

who may not be able to make the best use of it, and at worst, are creating incentives for implicit, if not explicit, collusion which both harms the taxpayer and cellular consumers who will have to wait longer before the spectrum finds its way to firms best able to provide cellular services.

\section{REFERENCES}

Ayres, I. and Cramton, P. (1996). "Deficit Reduction Through Diversity: How Affirmative Action at the FCC Increased Auction Competition." Stanford Law Review, 48 (4), 761-815.

Ausubel, L. M., Cramton, P., Mcafee, R. P., and Mcmillan, J. (1997). "Synergies in Wireless Telephony: Evidence from the Broadband PCS Auctions." Journal of Economics \& Management Strategy, 6 (3), 497-527.

Bennett, R. (2014). "Presenting the Technical Facts - High-Band vs. Low-Band Spectrum Deployment in Today's Spectrum-Constrained Environment." High Tech Forum. Retrieved July 10, 2016, from http://hightechforum.org/spectrum-deployment/

Bohlin, E., Madden, G. and Morey, A. (2010). "An Econometric Analysis of 3G Auction Spectrum Valuations.” EUI Working Papers, RSCAS 2010/55.

Brusco, S., Lopomo, G. and Marx, L. (2009). "The 'Google effect' in the FCC's $700 \mathrm{MHz}$ auction." Information Economics and Policy. 21 (2), 101-114.

Ciccone, A. and Hall, R. E. (1996). Productivity and the Density of Economic Activity. The American Economic Review, 86 (1), 54-70.

Coase, R.H. (1959) “The Federal Communications Commission.” Journal of Law and Economics, vol. 2, 1-40.

Congressional Budget Office. (2005). "Small Bidders in License Auctions for Wireless Personal Communications Services." Retrieved from https://www.cbo.gov/sites/default/files/109th-congress-2005-2006/reports/10-24-fcc.pdf

Connolly, M., Salisbury, R., Trivedi, A. and Zaman, A. (2017a). "FCC Spectrum Auction Rules." working paper, Duke University.

Connolly, M., Zrenner, A. and Nnoromele, C. (2017b). "The Impact of Small Bidder Preferences in FCC Spectrum Auctions." Working paper, Duke University.

Cramton, P. (2002). "Spectrum Auctions." in M. Cave, S. K. Majumdar, \& I. Vogelsang (Eds.), Handbook of Telecommunications Economics. (pp. 605-639). Amsterdam: Elsevier.

Cramton, P. (2012). "Declaration of Peter Cramton." in Verizon Wireless spectrum transaction with SpectrumCo and Cox, Federal Communications Commission, WT Docket No. 12-4. 
Evolution of spectrum values 34

Crawford, G., Kwerel, E. and Levy, J. (2008). “Economics at the FCC 2007-2008." Review of Industrial Organization, 33 (3), 187-210.

D.C. Circuit U.S. Court of Appeals. (2017) "SNR WIRELESS LICENSE CO, LLC, v. FEDERAL COMMUNICATIONS COMMISSION.” No. 15-1330, August 17.

DotEcon Spectrum Awards Database. (2015).

47 C.F.R. $§ 1.2110$ (2012).

Dippon, C. (2009). "Regulatory Policy Goals and Spectrum Auction Design: Lessons from the Canadian AWS Auction.” NERA Economic Consulting, July 14.

FCC (1997). "The FCC Report to Congress on Spectrum Auctions.” Wireless

Telecommunications Bureau, WT Docket No 97-150.

FCC (2000). "Sixth Report and Order and Order on Reconsideration." FCC 00-313, WT Docket No. 97-82.

FCC (2010). "Connecting America: The National Broadband Plan."

http://transition.fcc.gov/national-broadband-plan/national-broadband-plan.pdf

FCC (2015). "Order to Deny Small Business Credits to Northstar and SNR Wireless."

https://www.fcc.gov/document/order-deny-small-business-credits-northstar-snr-wireless

FCC, FCC Auctions: All Auctions, http://wireless.fcc.gov/auctions/default.htm?job=auctions_all

Ford, G. S. (2008). "Valuing the AWS-3 Spectrum: A Response to Comments." SSRN Electronic Journal. doi:10.2139/ssrn.1186222

Ford, G, Koustky, T. and Spiwak, L. (2008). "Using Auction Results to Forecast the Impact of Wireless Carterfone Regulation on Wireless Networks." Phoenix Center Policy Bulletin, No. 20.

Fox, J. T. and Bajari, P. (2013). "Measuring the Efficiency of an FCC Spectrum Auction." American Economic Journal: Microeconomics. 5 (1), 100-146.

Fujita, M., Krugman, P. R., \& Venables, A. (1999). The spatial economy: Cities, regions and international trade. Cambridge, MA: MIT Press.

Fujita, M., and Thisse, J. (2002). Economics of agglomeration: Cities, industrial location, and regional growth. Cambridge, UK: Cambridge University Press.

Hazlett, T. (2008). "Property Rights and Wireless License Values." The Journal of Law \& Economics, 51(3), 563-598.

Hazlett, T. and Muñoz, R. (2009). "A Welfare Analysis of Spectrum Allocation Policies." RAND Journal of Economics, 40 (3), 424-454.

Hazlett, T., Muñoz, R. and Avanzini (2012). "What Really Matters in Spectrum Allocation Design." Northwestern Journal of Technology and Intellectual Property, 10 (3), 93-123.

ITU (2012). "Exploring the Value and Economic Valuation of Spectrum." Telecommunication Development Bureau, ITU Broadband Series. 
Evolution of spectrum values 35

ITU (2014). "The World in 2014: ICT Facts and Figures." url: http://www.itu.int/en/ITUD/Statistics/Documents/facts/ICTFactsFigures2014-e.pdf

Kavalar, A. (2013). "Do Secondary Markets Undo Auctions? Long-Run Effects of Eligibility Restrictions on the Structure of the Market for Broadband PCS Spectrum." Doctoral Dissertation, University of California, Los Angeles.

Kerans, A., Vo, D., Conder, P., and Krusevac, S. (2011). "Pricing of spectrum based on physical criteria." 2011 IEEE International Symposium on Dynamic Spectrum Access Networks $(D y S P A N)$.

Klemperer, P. (2002a). "What Really Matters in Auction Design." Journal of Economic Perspectives, 16, 169-89.

Klemperer, P. (2002b). "How (Not) to Run Auctions: the European 3G Telecom Auctions." European Economic Review. 46, 829-45.

Kwerel, E. and G. Rosston (2000), “An Insider's View of FCC Spectrum Auctions," Journal of Regulatory Economics. 17 (3), 253-289.

Marks, P., Pearson, K., Williamson, B., Hansell, P and Burns, J. (2009). "Estimating the Commercial Trading Value of Spectrum: A Report for Ofcom." Plum Consulting, July 2.

Martin, R., Gardiner, B. and Tyler, P. (2014). The evolving economic performance of UK cities: City growth patterns 1981-2011 (United Kingdom, Government Office for Science).

Mcmillan, J. (1995). “Why auction the spectrum?” Telecommunications Policy, 19 (3), 191-199.

Moreton, P. and Spiller, P. (1998). "What's in the Air: Interlicense Synergies in the Federal Communications Commission's Broadband Personal Communication Service Spectrum Auctions." The Journal of Law and Economics. 41(S2), 677-716.

OOKLA, OOKLA.com

Randolph, K. (2011). Spectrum Licenses: Valuation Intricacies (Rep.).

Rappaport, T., Sun, S., Mayzus, R., Zhao, H., Azar, Y., Wang, K., Wong, G.N., Schulz, J.K., Samimi, M., Gutierrez, F. (2013). "Millimeter wave mobile communications for 5G cellular: It will work!” IEEE Access, Vol. 1, 335-349.

Rosston, G. (2014). "Increasing the Efficiency of Spectrum Allocation." Review of Industrial Organization. 45 (3), 221-243.

Rumney, M. (2007). "What Next for Mobile Telephony? Examining the trend towards high-datarate networks." Agilent Measurement Journal, Issue 3, 32-37.

Rumney, M. (2009). "LTE and the Evolution to 4G Wireless: Design and Measurement Challenges." Keysight Technologies Publication.

"Spectral efficiency." Wikipedia, url: https://en.wikipedia.org/wiki/Spectral_efficiency 
Evolution of spectrum values 36

Strange, W.C. (2016) "Urban Agglomeration." The New Palgrave Dictionary of Economics. Second Edition. Eds. Steven N. Durlauf and Lawrence E. Blume. Palgrave Macmillan.

Varrall, G. (2012). "Wireless User Hardware.” In Making Telecoms Work: From Technical Innovation to Commercial Success.

Vickrey, W. (1961). "Counterspeculation, Auctions and Competitive Sealed Tenders." Journal of Finance, 16, 8-39.

Wallsten, S. (2013). "Is There Really a Spectrum Crisis? Quantifying the Factors Affecting Spectrum License Value." SSRN Electronic Journal. doi:10.2139/ssrn.2206466

\section{APPENDIX}

\section{A1. Note on Data Manipulation}

From the raw DotEcon data, we first drop 36 observations that do not have a listed headline price. We also drop any observation that does not have a population associated with it, such as radio frequencies over areas such as the Gulf of Mexico. This only affects 17 observations, most of which are radio. Finally, we drop any observations whose reserve price is strictly greater than the headline price. This results in the loss of another 58 observations.

\section{A2. Merging Auction Block Rules Data and License Auction Data}

Within each auction, the FCC assigns licenses to different blocks, with specific rules for each block within an auction. For example, some blocks have rules restricting participation in the auction, while other blocks restrict the usage of spectrum in some way. To merge the data collected from the FCC auction rules and the auction data itself, it is necessary to identify the block of each auction. Unfortunately, the auction data set does not specify the block for each license. Instead, the auction data set has a "lot name" (also called item name in similar data sets). The block to which the license belongs can be extracted from the lot name, although the process is not always obvious. To facilitate reproducibility, we provide Table 6A which lists (for all cellular auctions) the auction number, the possible blocks in the auction, an example lot name, and the process by which the block can be extracted from the lot name. 
Evolution of spectrum values 37

Table 1A. Identification of Blocks

\begin{tabular}{|c|c|c|c|}
\hline $\begin{array}{l}\text { Auction } \\
\text { Number }\end{array}$ & Blocks & $\begin{array}{l}\text { Example Lot } \\
\text { Name }\end{array}$ & Extraction Procedure \\
\hline 1 & $\begin{array}{l}\text { N-1,N-2,N-3,N-4,N-5,N-6,N-7,N- } \\
8, N-9, N-10, N-11\end{array}$ & $\mathrm{~N}-1$ & Block is the same as lot name \\
\hline 3 & $1,2,3,4,5,6$ & Frequency2 & Block is last digit in lot name \\
\hline 4 & A,B & $29 \mathrm{~A}$ & Block is last character in lot name \\
\hline 5 & $\mathrm{C}$ & PBB138C & Block is last character in lot name \\
\hline 10 & $\mathrm{C}$ & PBB133C & Block is last character in lot name \\
\hline 11 & $\mathrm{D}, \mathrm{E}, \mathrm{F}$ & $\mathrm{D}$ & Block is the same as lot name \\
\hline 22 & $\mathrm{C}, \mathrm{D}, \mathrm{E}, \mathrm{F}$ & PBB396C2 & $\begin{array}{l}\text { Block is last non-numeric character in } \\
\text { lot name }\end{array}$ \\
\hline 33 & A,B & WXMEA003B & Block is last character in lot name \\
\hline 35 & $\mathrm{C}, \mathrm{F}$ & CWB036C4 & $\begin{array}{l}\text { Block is last non-numeric character in } \\
\text { lot name }\end{array}$ \\
\hline 38 & A,B & WXMEA014B & Block is last character in lot name \\
\hline 41 & $\begin{array}{l}\text { NW-18, NW-19, NW-20, NW-21, } \\
\text { NW-22, NW-23, NW-24, NW-25, } \\
\text { MTA-26, MTA-27, MTA-28, MTA- } \\
\text { 29, MTA-30, MTA-31, MTA-32 }\end{array}$ & $\begin{array}{l}\text { CNMTA01327, } \\
\text { CNNWA25522 }\end{array}$ & $\begin{array}{l}\text { To get the block name, take three } \\
\text { characters after "CN" if the third is an } \\
\text { "M" and two characters if it is an "N," } \\
\text { add a "-," and take the last two digits }\end{array}$ \\
\hline 44 & $\mathrm{C}, \mathrm{D}$ & WZ-CMA462-C & Block is last character in lot name \\
\hline 49 & C,D & WZ-CMA498-C & Block is last character in lot name \\
\hline 50 & $\begin{array}{l}\text { MTA-26,MTA-27, MTA-28, MTA- } \\
\text { 29, MTA-30, MTA-31, MTA-32 }\end{array}$ & $\begin{array}{l}\text { CN-MTA003- } \\
31\end{array}$ & $\begin{array}{l}\text { Block is "MTA-" followed by the last } \\
\text { two digits of the lot name }\end{array}$ \\
\hline 56 & $35,36,37,38,39$ & T2-BEA141-37 & Block is last two digits of lot name \\
\hline 58 & $\mathrm{~A}, \mathrm{~B}, \mathrm{C}, \mathrm{D}, \mathrm{E}, \mathrm{F}$ & $\begin{array}{l}\text { CW-BTA329- } \\
\text { C3 }\end{array}$ & $\begin{array}{l}\text { Block is last non-digit character of lot } \\
\text { name }\end{array}$ \\
\hline 66 & $\mathrm{~A}, \mathrm{~B}, \mathrm{C}, \mathrm{D}, \mathrm{E}, \mathrm{F}$ & $\begin{array}{l}\text { AW-CMA616- } \\
\text { A }\end{array}$ & Block is last character of lot name \\
\hline 71 & $\mathrm{~A}, \mathrm{~B}, \mathrm{C}, \mathrm{D}, \mathrm{E}, \mathrm{F}$ & $\begin{array}{l}\text { DW-BTA020- } \\
\text { C5 }\end{array}$ & $\begin{array}{l}\text { Block is last non-digit character of lot } \\
\text { name }\end{array}$ \\
\hline 73 & $\mathrm{~A}, \mathrm{~B}, \mathrm{C}, \mathrm{D}, \mathrm{E}, \mathrm{F}$ & $\begin{array}{l}\text { WY-CMA170- } \\
\text { B }\end{array}$ & Block is last character of lot name \\
\hline 78 AWS & $\mathrm{A}, \mathrm{B}, \mathrm{C}, \mathrm{D}, \mathrm{E}, \mathrm{F}$ & $\begin{array}{l}\text { AW-CMA377- } \\
\text { A }\end{array}$ & Block is last character of lot name \\
\hline $78 \mathrm{PCS}$ & $\mathrm{C} 1, \mathrm{C} 3, \mathrm{C} 4, \mathrm{C} 5, \mathrm{D}, \mathrm{E}, \mathrm{F}$ & $\begin{array}{l}\text { CW-CMA170- } \\
\text { C5 }\end{array}$ & $\begin{array}{l}\text { Block consists of all characters after } \\
\text { the final dash in lot name }\end{array}$ \\
\hline 92 & $\mathrm{~A}, \mathrm{~B}$ & $\begin{array}{l}\text { WY-CMA663- } \\
\text { B }\end{array}$ & Block is final character of lot name \\
\hline 96 & $\mathrm{H}$ & AH-BEA165-H & Block is final character of lot name \\
\hline 97 & $\mathrm{~A} 1, \mathrm{~B} 1, \mathrm{G}, \mathrm{H}, \mathrm{I}, \mathrm{J}$ & $\begin{array}{l}\text { AW-CMA39- } \\
\text { B1 }\end{array}$ & $\begin{array}{l}\text { Block consists of all characters after } \\
\text { the final dash in lot name }\end{array}$ \\
\hline
\end{tabular}

The DotEcon auction data set includes the variable region, which gives the area covered by the spectrum for that license. We have separate data from OOKLA on upload and download speeds for fixed broadband in various cities in the United States at various times. These speeds 
Evolution of spectrum values 38

serve as a proxy for communications infrastructure. A city with fast fixed broadband likely also has significant existing infrastructure for cellular data transmission, reducing the investment necessary for a cellular company to fully utilize the spectrum.

To include this information in our analysis, it is necessary to merge these two data sets. The task is rather tedious, and for a complete understanding it is necessary to review the code that performs the merge. In general, we identify a pattern, format the regions that fit that pattern, and then move on to the next pattern. The table below gives some examples of regions in our data set and the city/state pairing that was used in the merge.

Table 2A. Matching License Region to City

\begin{tabular}{|l|l|}
\hline Region (DotEcon Identification) & City Used in Match \\
\hline Buffalo-NiagaraFallsNY-PABEA & Buffalo, NY \\
LasCruces,NMBTA & Las Cruces, NM \\
Arkansas9-PolkCMA & Polk, AR \\
SoutheastEAG & No match found \\
TulsaMTA & Tulsa, OK \\
Nationalnationwide & No match found \\
AlaskaMTA & Alaska \\
Alaska2-BethelCMA & No match found \\
Louisiana2-MorehouseCMA & Morehouse Parish, LA \\
\hline
\end{tabular}

As can be seen in the examples above, many regions have a code (BEA, BTA, CMA, EAG, MTA) that specifies the type of region. Some licenses are identified with a specific city (Tulsa, in the example above). If there is only one city with a given name in our data set (such as Tulsa, above), we can identify the state in which it is located even if the two letter abbreviate is not found in the region code.

Other licenses divide the state into numbered regions, which are associated with a specific city. For these, it is easy to identify the state, convert it to the state's two letter abbreviation, and append it to the city. See the Arkansas9-PolkCMA example above.

Alaska and Hawaii are often (but not always) covered by a single license. In these cases, we did not match the license to the broadband data in a specific city. On one hand, there are large cities (Anchorage and Honolulu, specifically) in these states where most cellular customers are likely concentrated. This might suggest that the speeds in these cities are highly relevant. On the other hand, there are large sparsely populated areas outside of these cities that may 
Evolution of spectrum values 39

require a significant investment in infrastructure. In the cases where Alaska was divided into regions, the broadband data often lacked information on relevant Alaskan cities. See the Alaska2-BethelCMA example in the table.

Some city names consist of multiple words, such as New York City. The region is often indicated in mixed case, for example NewYorkCity. In such cases, it is easy to use regular expressions to split the mixed case phrase into separate words. Difficulties arise from foreign names, such as Fond du Lac, WI. These cases are identified and manually changed. In Louisiana, we often have parish level data. It is necessary to add "Parish" to these manually, such as in the case of Louisiana2-MorehouseCMA.

We often have multiple observations within a year for a given location. For each license, we elect the speed measurement that minimizes the distance between the dates of the observation and the auction. The earliest measurement in the data occurred 2008, so we restrict our matches to those auctions that occurred in 2007 or later. In other words, we will match auctions in 2007 with the earliest relevant measurement in 2008 . We do not match any auctions before 2007, as the rapid changes increases in speed suggest that we would be drastically overestimating the true speed with such a match. I.e., we believe extrapolating one year may be reasonable, but two years would be excessive. 


\section{Evolution of spectrum values 40}

Table 3A. Log Real Headline Price - Tobit Regressions

\begin{tabular}{|c|c|c|c|c|}
\hline & \multicolumn{2}{|c|}{$1997-2015$} & \multicolumn{2}{|c|}{$2007-2015$} \\
\hline License Traits & & & & \\
\hline License Bandwidth & $\begin{array}{c}0.492 \\
(32.45)\end{array}$ & $\begin{array}{c}0.479 \\
(33.15)\end{array}$ & $\begin{array}{c}0.623 \\
(20.12)\end{array}$ & $\begin{array}{c}0.582 \\
(18.66)\end{array}$ \\
\hline License Bandwidth Squared & $\begin{array}{l}-0.0132 \\
(-29.93)\end{array}$ & $\begin{array}{l}-0.0120 \\
(-28.45)\end{array}$ & $\begin{array}{l}-0.0189 \\
(-17.23)\end{array}$ & $\begin{array}{l}-0.0172 \\
(-15.50)\end{array}$ \\
\hline Paired Band & $\begin{array}{l}0.542 \\
(5.83)\end{array}$ & $\begin{array}{l}0.308 \\
(3.46)\end{array}$ & $\begin{array}{l}0.266 \\
(2.70)\end{array}$ & $\begin{array}{l}0.248 \\
(2.54)\end{array}$ \\
\hline $\begin{array}{r}\text { Frequencies between } \\
1000 \text { and } 2000 \mathrm{MHz}\end{array}$ & $\begin{array}{l}0.148 \\
(3.97)\end{array}$ & $\begin{array}{c}-0.0159 \\
(-0.44)\end{array}$ & $\begin{array}{l}0.312 \\
(1.97)\end{array}$ & $\begin{array}{l}0.235 \\
(1.51)\end{array}$ \\
\hline $\begin{array}{r}\text { Frequencies above } \\
2000 \mathrm{MHz}\end{array}$ & $\begin{array}{c}-1.881 \\
(-29.70)\end{array}$ & $\begin{array}{c}-1.625 \\
(-26.49)\end{array}$ & $\begin{array}{l}-0.152 \\
(-0.54)\end{array}$ & $\begin{array}{l}-0.279 \\
(-1.00)\end{array}$ \\
\hline High Frequency Effect after MIMO & $\begin{array}{l}2.660 \\
(21.10)\end{array}$ & $\begin{array}{c}2.307 \\
(19.11)\end{array}$ & $\begin{array}{l}1.618 \\
(4.99)\end{array}$ & $\begin{array}{l}1.562 \\
(4.90)\end{array}$ \\
\hline Closed License & $\begin{array}{c}-0.0369 \\
(-0.80)\end{array}$ & $\begin{array}{l}0.0254 \\
(0.58)\end{array}$ & $\begin{array}{l}-0.381 \\
(-1.66)\end{array}$ & $\begin{array}{l}-0.426 \\
(-1.89)\end{array}$ \\
\hline $\begin{array}{r}\text { Auction } 73 \mathrm{C} \text { block licenses with Open } \\
\text { Access Requirement }\end{array}$ & $\begin{array}{l}-0.638 \\
(-1.78)\end{array}$ & $\begin{array}{l}-0.615 \\
(-1.81)\end{array}$ & - & $\begin{array}{l}0 \\
(.)\end{array}$ \\
\hline Bidding Credit Used in Winning Bid & $\begin{array}{c}-0.358 \\
(-12.63) \\
\end{array}$ & $\begin{array}{c}-0.358 \\
(-13.34) \\
\end{array}$ & $\begin{array}{c}-0.481 \\
(-11.55) \\
\end{array}$ & $\begin{array}{c}-0.504 \\
(-12.18)\end{array}$ \\
\hline \multicolumn{5}{|l|}{ Market } \\
\hline Population (Logs) & $\begin{array}{c}1.214 \\
(90.26)\end{array}$ & $\begin{array}{l}1.178 \\
(91.57)\end{array}$ & $\begin{array}{c}1.199 \\
(67.63)\end{array}$ & $\begin{array}{c}1.192 \\
(68.16)\end{array}$ \\
\hline Population Density (Logs) & $\begin{array}{c}0.00867 \\
(0.76)\end{array}$ & $\begin{array}{c}0.00326 \\
(0.30)\end{array}$ & $\begin{array}{l}0.125 \\
(8.36)\end{array}$ & $\begin{array}{l}0.120 \\
(8.11)\end{array}$ \\
\hline Real Median Income (Logs) & $\begin{array}{c}1.020 \\
(13.49)\end{array}$ & $\begin{array}{c}0.937^{* * *} \\
(13.06)\end{array}$ & $\begin{array}{c}1.270 \\
(12.35)\end{array}$ & $\begin{array}{c}1.179 \\
(11.56)\end{array}$ \\
\hline $\begin{array}{r}\text { Infrastructure Proxy: } \\
\text { Avg. Download speed (Mbps) in License } \\
\text { Area }\end{array}$ & & & $\begin{array}{c}0.00162 \\
(0.69)\end{array}$ & $\begin{array}{l}0.00152 \\
(0.65)\end{array}$ \\
\hline \multicolumn{5}{|l|}{ National } \\
\hline $\begin{array}{r}\text { Spectral Efficiency per Site } \\
\text { (bit/S/Hz/site) }\end{array}$ & $\begin{array}{c}-0.121 \\
(-24.71)\end{array}$ & $\begin{array}{l}-0.0887 \\
(-18.26)\end{array}$ & $\begin{array}{l}-0.0740 \\
(-9.39)\end{array}$ & $\begin{array}{l}-0.0777 \\
(-10.00)\end{array}$ \\
\hline NASDAQ & $\begin{array}{c}0.00124 \\
(39.12)\end{array}$ & $\begin{array}{c}0.000885 \\
(26.34)\end{array}$ & $\begin{array}{c}0.000303 \\
(3.76)\end{array}$ & $\begin{array}{c}0.000411 \\
(5.10)\end{array}$ \\
\hline \multicolumn{5}{|l|}{ Auction Competition } \\
\hline $\begin{array}{r}\text { Total Spectrum Offered } \\
\text { in Auction }\end{array}$ & $\begin{array}{l}0.0000527 \\
(16.86)\end{array}$ & $\begin{array}{l}0.0000393 \\
(12.61)\end{array}$ & $\begin{array}{l}0.0000692 \\
(15.38)\end{array}$ & $\begin{array}{l}0.0000575 \\
(12.25)\end{array}$ \\
\hline \# bidders for license & & $\begin{array}{l}0.208 \\
(11.09)\end{array}$ & & $\begin{array}{l}0.0903 \\
(2.74)\end{array}$ \\
\hline \# of bidders for license squared & & $\begin{array}{c}-0.00441 \\
(-2.95)\end{array}$ & & $\begin{array}{c}-0.000566 \\
(-0.22)\end{array}$ \\
\hline Constant & $\begin{array}{c}-19.40 \\
(-25.16)\end{array}$ & $\begin{array}{c}-17.85 \\
(-24.32)\end{array}$ & $\begin{array}{c}-20.67 \\
(-19.44)\end{array}$ & $\begin{array}{c}-19.84 \\
(-18.78)\end{array}$ \\
\hline Ln Sigma Constant & $\begin{array}{c}-0.00981 \\
(-1.14) \\
\end{array}$ & $\begin{array}{c}-0.0604 \\
(-6.94) \\
\end{array}$ & $\begin{array}{c}-0.348 \\
(-22.43) \\
\end{array}$ & $\begin{array}{c}-0.363 \\
(-23.38) \\
\end{array}$ \\
\hline Obs. & 7134 & 7109 & 2082 & 2080 \\
\hline Auctions Included & \multicolumn{2}{|c|}{$\begin{array}{c}11,22,33,35,38,44,49,58,66,71,73,78,92 \\
96,97\end{array}$} & \multicolumn{2}{|c|}{$71,73,78,92,96,97$} \\
\hline Auction Years (Start Dates) & \multicolumn{2}{|c|}{$\begin{array}{c}1997,1999,2000,2001,2002,2003,2005 \\
2006,2007,2008,2011,2014\end{array}$} & \multicolumn{2}{|c|}{$2007,2008,2011,2014$} \\
\hline
\end{tabular}

